\title{
Ambient Factors Controlling the Wintertime Precipitation Distribution across Mountain Ranges in the Interior Western United States. Part II: Changes in Orographic Precipitation Distribution in a Pseudo-Global Warming Simulation
}

\author{
XIAOQIN JING \\ Collaborative Innovation Center on Forecast and Evaluation of Meteorological Disasters, School of \\ Atmospheric Physics, Nanjing University of Information Science and Technology, Nanjing, China \\ BART GEERTS \\ Department of Atmospheric Science, University of Wyoming, Laramie, Wyoming \\ YONGGANG WANG \\ Department of Geosciences, Texas Tech University, Lubbock, Texas \\ CHANGHAi LIU \\ National Center for Atmospheric Research, ${ }^{\text {a }}$ Boulder, Colorado
}

(Manuscript received 27 June 2018, in final form 12 January 2019)

\begin{abstract}
Two high-resolution $(4 \mathrm{~km})$ regional climate simulations over a 10-yr period are conducted to study the changes in wintertime precipitation distribution across mountain ranges in the interior western United States (IWUS) in a warming climate. One simulation represents the current climate, and another represents an $\sim 2050$ climate using a pseudo-global warming approach. The climate perturbations are derived from the ensemble mean of 15 global climate models from phase 5 of the Coupled Model Intercomparison Project (CMIP5). These simulations provide an estimate of average changes in wintertime orographic precipitation enhancement and finescale distribution across mountain ranges. The variability in these changes among CMIP5 models is quantified using statistical downscaling relations between orographic precipitation distribution and upstream conditions, developed in Part I. The CMIP5 guidance indicates a robust warming signal $(\sim 2 \mathrm{~K})$ over the IWUS by $\sim 2050$ but minor changes in relative humidity and cloud-base height. The IWUS simulations reveal a widespread increase in precipitation on account of higher precipitation rates during winter storms in this warmer climate. This precipitation increase is most significant over the mountains rather than on the surrounding plains. The increase in precipitation rate is largely due to an increase in low-level cross-mountain moisture transport. The application of the statistical relations indicates that individual CMIP5 models disagree about the magnitude and distribution of orographic precipitation change in the IWUS, although most agree with the ensemble-mean-predicted orographic precipitation increase.
\end{abstract}

\section{Introduction}

Wintertime orographic precipitation distribution across mountain ranges is strongly controlled by ambient conditions (Yuter et al. 2011; Houze 2012). Among various ambient factors, low-level cross-mountain wind speed

\footnotetext{
${ }^{a}$ The National Center for Atmospheric Research is sponsored by the National Science Foundation.
}

Corresponding author: Bart Geerts, geerts@uwyo.edu and moisture flux have the most significant impact on orographic precipitation rate (Colle 2004; James and Houze 2005; Panziera and Germann 2010; Yuter et al. 2011; Jing et al. 2018). Other factors, such as cloud-base temperature (CBT) and cloud-base height (CBH), lowlevel stability, and cloud types, also affect the precipitation amount and distribution across mountain ranges (Zängl 2008; Geerts et al. 2015). We examined this in Jing et al. (2018, hereinafter Part I), using a 10-yr-long, 4-kmresolution regional climate simulation over the interior western United States (IWUS), and developed statistical 
relations between these ambient conditions and the enhancement and spatial distribution of orographic precipitation for selected mountain ranges.

The question addressed here, in Part II, is how future changes in ambient conditions, in a changing global climate, influence the orographic precipitation distribution. The impact of a changing climate on winter precipitation and snowpack over mountains is of interest in many respects, such as ecosystems and water supplies (Mote et al. 2005; Milly et al. 2008; Luce et al. 2013). Mote et al. (2005) showed that a widespread decline of the mountain snowpack is taking place in the western United States. Das et al. (2011) showed streamflow declines in the Colorado, Columbia, and San Joaquin-Sacramento basins in a warming climate, using hydrological models. Some studies have attributed the observed declines of snowpack and streamflow in the mountainous western United States to the higher evapotranspiration (ET) and earlier snowmelt in a global warming environment $(\mathrm{Fu}$ et al. 2010; Das et al. 2011), but Luce et al. (2013) showed that the increased ET and earlier snowmelt cannot fully explain the decline of streamflow, at least around the Cascades Range; they suggested that the decline of streamflow is at least partly due to dwindling wintertime precipitation at high altitudes, which they attributed to weaker cross-mountain wind speed and reduced orographic enhancement. For other mountain ranges, such as those in the IWUS, wind speed may not be the dominant factor controlling the changes in precipitation distribution (Dettinger 2014). The winter precipitation efficiency over mountain ranges in Colorado and Utah is expected to be lower in a warmer climate because of the higher temperature and thus warmer cloud base (Eidhammer et al. 2018). Other studies have demonstrated a likely increase in wintertime precipitation in the IWUS in a warmer climate (Rasmussen et al. 2011, 2014; Liu et al. 2017). None of these studies have explored changes in precipitation distribution across mountain ranges, into different watersheds.

This study aims to explore how future changes in atmospheric conditions may influence wintertime orographic precipitation in the IWUS, home to the headwaters of several major river systems, in particular the Colorado, Missouri, and Snake Rivers. In the current climate virtually all the precipitation in winter falls as snow over the mountain ranges studied herein. Questions related to climatic changes in snow-rain partitioning and in seasonal snowpack evolution are very important in the relatively arid IWUS (e.g., Rasmussen et al. 2014), but they are not addressed here. In the IWUS, most of the precipitation falls in the cold season, and mostly over the mountain ranges, while the surrounding high plains and basins are relatively dry (Jing et al. 2017).
This study employs the regional climate model framework used in Part I both under current climate conditions $(\sim 2000)$ and under future climate conditions ( 2050). The climate perturbation to the driver dataset for the future simulation is given by the 15 -member ensemble mean from phase 5 of the Coupled Model Intercomparison Project (CMIP5; Hurrell et al. 2011). The resulting regional climate simulation illuminates how orographic precipitation will change in the CMIP5 ensemble-mean change scenario. There is much variability between the 15 GCM members, but GCMs lack the spatial resolution to capture individual mountain ranges within the IWUS, and thus the local orographic precipitation enhancement. The GCMs do capture the synoptic conditions. Therefore, this study uses the statistical relations between orographic precipitation distribution and upstream synoptic conditions developed in Part I to quantify the uncertainty in the orographic precipitation response.

The paper is organized as follows: section 2 describes the approach and analysis method, section 3 shows the results, and a discussion and conclusions are given in sections 4 and 5 , respectively.

\section{Model simulations and analysis method}

\section{a. Simulation of the historical precipitation climatology}

This study uses a 4-km-grid-spacing, convection-permitting regional climate model simulation introduced and validated in Wang et al. (2018). The simulation was run over 30 years (October 1981-February 2012) ${ }^{1}$ over a domain that stretches diagonally from northeastern Washington State to southwestern Oklahoma (Wang et al. 2018). Only this domain's inner portion, shown in Fig. 1a, is examined here. The detailed WRF Model setup and physics choices of this "IWUS" simulation are described in Jing et al. (2017) and Wang et al. (2018). The simulation is driven by the Climate Forecast System Reanalysis (CFSR; Saha et al. 2010). The model domain has $420 \times$ 410 grid points and 51 vertical levels. The model is driven entirely by initial and boundary information; that is, no nudging of any kind toward observed conditions is applied within the domain. The key physics choices are the Thompson bulk cloud microphysics scheme (Thompson et al. 2008), the Noah-MP land surface scheme (Niu et al. 2011; Yang et al. 2011), the revised MoninObukhov surface layer scheme (Jimenez et al. 2012), the Yonsei University planetary boundary layer scheme

\footnotetext{
${ }^{1}$ The simulation has since been extended to more recent years.
} 

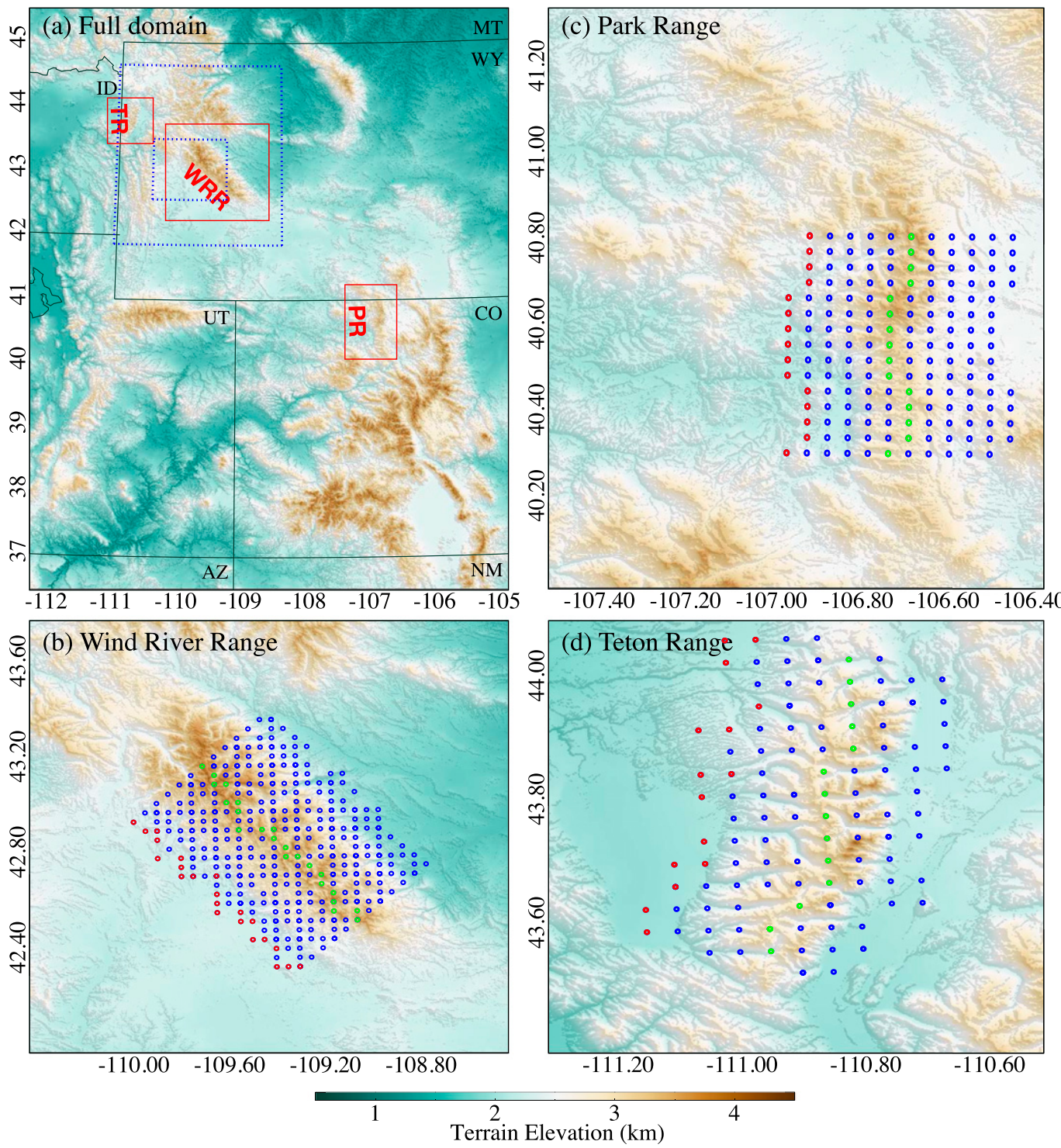

FIG. 1. The topography of the (a) full domain of interest $(\mathrm{TR}=$ Teton Range, WRR $=$ Wind River Range, and PR = Park Range), (b) Wind River Range, (c) Park Range, and (d) Teton Range. The red boxes in (a) show the locations of the domains of (b)-(d). The blue dashed boxes in (a) represent the horizontal resolution of two GCMs: the smaller one is for CESM1(CAM5), and the larger one is for MIROC-ESM. The circles (red, green, and blue) in (b)-(d) indicate the grid points used to plot the mean cross sections of precipitation. The red circles represent the grid points used to calculate upwind atmospheric conditions. The green circles represent the mountain crest.

(Hong and Pan 1996), and the Rapid Radiative Transfer Model for General Circulation Models (RRTMG) shortwave and longwave radiation scheme (Iacono et al. 2008).

Here hourly output of the IWUS simulation for 10 winters (defined in this study as December-February) is used, from December 2003 to February 2012. The modeled precipitation compares well to gauge data and to gauge-driven gridded datasets in all seasons, especially winter (Jing et al. 2017). In fact, Jing et al. (2017) provided circumstantial evidence for the claim that the IWUS model precipitation is more accurate than gauge-driven gridded estimates in the cold season, in particular over mountains with a sparse gauge network, such as Wyoming's Wind River Range, and pointed to likely significant errors in gridded estimates that arise from extrapolation across steep terrain gradients. For that reason the IWUS simulation 
can be used as a high-resolution atmospheric reanalysis product.

\section{b. Simulation of the $\sim 2050$ climatology}

A pseudo-global warming (PGW) approach (Schär et al. 1996) is used here to investigate how changes in ambient conditions (as predicted by the CMIP5 consensus by $\sim 2050$ ) affect the amount and distribution of winter snowfall in the IWUS. This technique has been used previously to investigate future changes in orographic precipitation and snowpack in the IWUS region (Rasmussen et al. 2011, 2014; Eidhammer et al. 2018) and changes in precipitation in the contiguous United States (Liu et al. 2017). The basic idea of the PGW approach is to apply the guidance from global climate models (in this case the ensemble-mean CMIP5 climate change signal) to the driver dataset of the RCM (Schär et al. 1996). The PGW technique allows climate change assessment assuming invariable low-frequency global atmospheric variability. That is, while the mean change of the baroclinic storm track is captured, the distribution of synoptic storms and the intra- to interannual atmospheric teleconnections are assumed not to change in a warming global climate. This choice is justified by an analysis of the CMIP5 GCM simulations, which indicates that thermodynamic changes in a globally warming climate (i.e., the warming and moistening of winter storms) overwhelm sustained changes associated with changes in internal climate variability (Gutmann et al. 2017). Still, one caveat of this study is that it captures the more predictable thermodynamic response of cold season precipitation to greenhouse gas emissions but does not incorporate alternative changes in the large-scale circulation in a warming climate (other than those captured by the CMIP5 ensemble mean; e.g., Bender et al. 2012; Deser et al. 2016).

In this study, the CFSR driver dataset is perturbed by the 60-yr consensus climate change signal (difference between 1990 and 2050) under the representative concentration pathway 8.5 (RCP8.5) emission scenario, which largely assumes "business as usual" in terms of anthropogenic greenhouse gas emissions (Riahi et al. 2011). The 4-km-resolution IWUS simulation was run identically over a 30 -yr period with the perturbed CFSR as driver, representing 2036-65. The physical fields perturbed in the PGW approach include 3D fields (temperature, geopotential, specific humidity, and horizontal wind) and surface fields (sea level pressure and soil temperature). Specifically, the monthly mean climate perturbations between a 30-yr future period centered at 2050 and a $30-\mathrm{yr}$ current period centered at 1990 , averaged over 15 CMIP5 members, are added to
TABLE 1. List of the 15 CMIP5 GCMs used in this study.

\begin{tabular}{lccc}
\hline \hline & $\begin{array}{c}\text { Horizontal } \\
\text { resolution } \\
(\text { lon } \times \text { lat; }\end{array}$ & $\begin{array}{c}\text { No. of } \\
\text { vertical } \\
\text { levels }\end{array}$ & $\begin{array}{c}\text { No. of } \\
\text { simulations } \\
\text { used }\end{array}$ \\
\hline ACCESS1.3 & $1.875 \times 1.25$ & 17 & 1 \\
CCSM4 & $1.25 \times 0.94$ & 17 & 3 \\
CESM1(CAM5) & $1.25 \times 0.94$ & 17 & 3 \\
CNRM-CM5 & $1.41 \times 1.40$ & 17 & 3 \\
CSIRO Mk3.6.0 & $1.88 \times 1.87$ & 18 & 3 \\
GFDL CM3 & $2.5 \times 2.0$ & 23 & 1 \\
GFDL-ESM2M & $2.5 \times 1.52$ & 17 & 1 \\
GISS-E2-H & $2.5 \times 2.0$ & 17 & 2 \\
HadGEM2-CC & $1.875 \times 1.20$ & 23 & 2 \\
HadGEM2-ES & $1.875 \times 1.25$ & 17 & 2 \\
INM-CM4 & $2.0 \times 1.5$ & 17 & 1 \\
IPSL-CM5A-MR & $2.50 \times 1.27$ & 17 & 1 \\
MIROC5 & $1.41 \times 1.40$ & 17 & 3 \\
MIROC-ESM & $2.81 \times 2.79$ & 35 & 1 \\
MRI-CGCM3 & $1.12 \times 1.12$ & 23 & 1 \\
\hline
\end{tabular}

the CFSR data that serve as WRF initial and boundary conditions:

$$
\mathrm{CFSR}_{\text {future }}=\mathrm{CFSR}+\left(\overline{\mathrm{CMIP5}}_{\sim 2050}-\overline{\mathrm{CMIP5}}_{\sim 1990}\right) .
$$

The 15 GCMs used in this study are listed in Table 1. As part of the Fifth Assessment Report by the Intergovernmental Panel on Climate Change (https://www.ipcc.ch/ report/ar5/), they were run for several emission scenarios out to 2050 and beyond. As seen from the blue boxes in Fig. 1a, the resolution of the GCMs, even the highest one [CESM1(CAM5)], is inadequate to resolve the IWUS mountain ranges. This study uses only 10 years of the IWUS current-climate simulation (called the control) and the corresponding 10 years of the IWUS future-climate simulation. A 30 -yr period is needed to examine extremes within a climate system, but 10 years suffice for the purpose of this study, which is to explore how the typical wintertime orographic precipitation in the IWUS is expected to change in a warmer climate and which factors dominate the change.

\section{c. Analysis method}

As in Part I, three mountain ranges are selected in this study: the Wind River Range, Park Range, and Teton Range (Figs. 1b-d). For each mountain range, we calculate the upwind atmospheric conditions during winter storms, and plot the mean cross sections of precipitation and parameters such as vapor flux and potential temperature from the control and future runs. The circles (of any color) in Figs. 1b-d indicate the grid points used to calculate the precipitation rate and to plot composite values in cross sections. The red circles are used to calculate the upwind ambient conditions, and the green 
circles denote the mountain crest. Since the mountain crest does not align in consecutive transects, the red circles are not along a straight line. The transects shown herein are based on an equal number of grid points on the windward and leeward sides for the Wind River and Park Ranges. There are proportionally more grid points on the windward side of the Teton Range, because of its asymmetry (steeper on the leeward side). Here "proportional" means that the fraction of the windward and leeward points are the same in each transects across the Mountain Range. As shown in Part I, flow from left to right (i.e., westerly or southwesterly lowlevel flow) prevails for the large majority of winter storms over these ranges, hence the upwind grid points are on the left.

The number of grid points capturing the select mountain ranges at a resolution of $4 \mathrm{~km}$ is limited (Fig. 1) and may not adequately capture orographic precipitation enhancement. We conducted a higherresolution $(1.33 \mathrm{~km})$ simulation for the steepest of the three mountains, the Teton Range, for the current climate. Such finer resolution resolves the precipitation texture relative to the terrain better; for instance, it predicts more and less precipitation over the narrow ridges and valleys, respectively, that emerge west of the Teton crest (Fig. 2), a pattern that has been demonstrated for the Oregon Cascades (Garvert et al. 2007) and the Olympic Mountains (Minder et al. 2008). It also predicts more precipitation in the lee of the Teton Range. The reason for this is uncertain: it is possible that a finer model resolution allows more low-level water vapor advection eastward through mountain gaps, especially on the south side of the range. Alternatively, there may be a change in the pattern of leeside subsidence.

A finer resolution better simulates orographic precipitation, not only because of the finescale terrain effects, but also because of its ability to capture orographic convection (Jing et al. 2017). However, this study aims to investigate how future changes in ambient conditions would influence the orographic precipitation rate and upwind precipitation fraction (UPF). We do not focus on the small-scale structure of orographic precipitation distribution. As shown in Part I, convection only accounts for a small fraction of the total wintertime precipitation. Thus, the 4-kmresolution simulation is sufficient to achieve our goal, but the limitation of the 4-km resolution needs to be kept in mind.

Five upwind factors have been shown in Part I to be important predictors for the orographic precipitation rate and the UPF in the current climate: the mountainnormal wind speed $U$, the Brunt-Väisälä frequency $N$, the CBT, the mixed-layer lifted condensation level (LCL), and the cloud depth (CD). These variables will therefore be investigated in the future climate. The definitions of theses variables are described in Part I.

\section{Results}

\section{a. Future changes in ambient conditions according to CMIP5}

In this section, we discuss the GCM projected future changes in ambient conditions in the IWUS. The 15-GCM ensemble-mean differences between 19762005 and 2035-2065 in the wintertime climate for the RCP8.5 emission scenario, corresponding to the climate signals that are applied along the boundaries of the IWUS WRF simulation, are shown in Fig. 3 over a larger domain encompassing much of North America. The wintertime surface temperature increases by $2.6 \mathrm{~K}$ on average in the IWUS (the domain shown in Fig. 1a), which is slightly larger than the $2.3 \mathrm{~K}$ global and annual mean change for the RCP8.5 scenario but not nearly as large as over the Hudson Bay and the Arctic in general. The weak local maximum warming in the IWUS (specifically, from Utah to southern Idaho) may be attributed to fewer occasions in a warmer climate on which the snow albedo-surface temperature feedback (Letcher and Minder 2015) comes into play: reduced snow cover and surface albedo (not shown) are predicted to weaken the persistent inversions often present in winter in the basins of the IWUS. This surface warming leads to a slight steepening of the average tropospheric lapse rate in the IWUS (Fig. 3c). The changes in specific humidity near the surface mirror the current specific humidity distribution, being higher over oceans than over the continent, and decreasing inland and northward (Fig. 3a). On average, specific humidity increases by $0.4-0.8 \mathrm{~g} \mathrm{~kg}^{-1}$ over the continental United States from 1976-2005 to 2035-65 (Fig. 3a). More moisture is advected into the IWUS from the southwest in the future climate (Fig. 3b). The relative humidity slightly changes by from $-2 \%$ to $1 \%$ over the contiguous United States at $700 \mathrm{hPa}$, and the change is approximately 0 in the IWUS. At $300 \mathrm{hPa}$, the increase in wintertime temperature and geopotential height generally is higher in the subtropical belt, consistent with previous studies (e.g., Lorenz and DeWeaver 2007). This results in a stronger subtropical jet, but little change in upper-level wind in Colorado and Wyoming (Fig. 3d). The changes in moisture advection, stability, and flow patterns lead to an increase in wintertime precipitation in the IWUS (Figs. 3e,f). The relative change is significant in the IWUS (e.g., $13 \%$ in Wyoming), although the absolute change is low when compared with some wet places such as the Pacific 

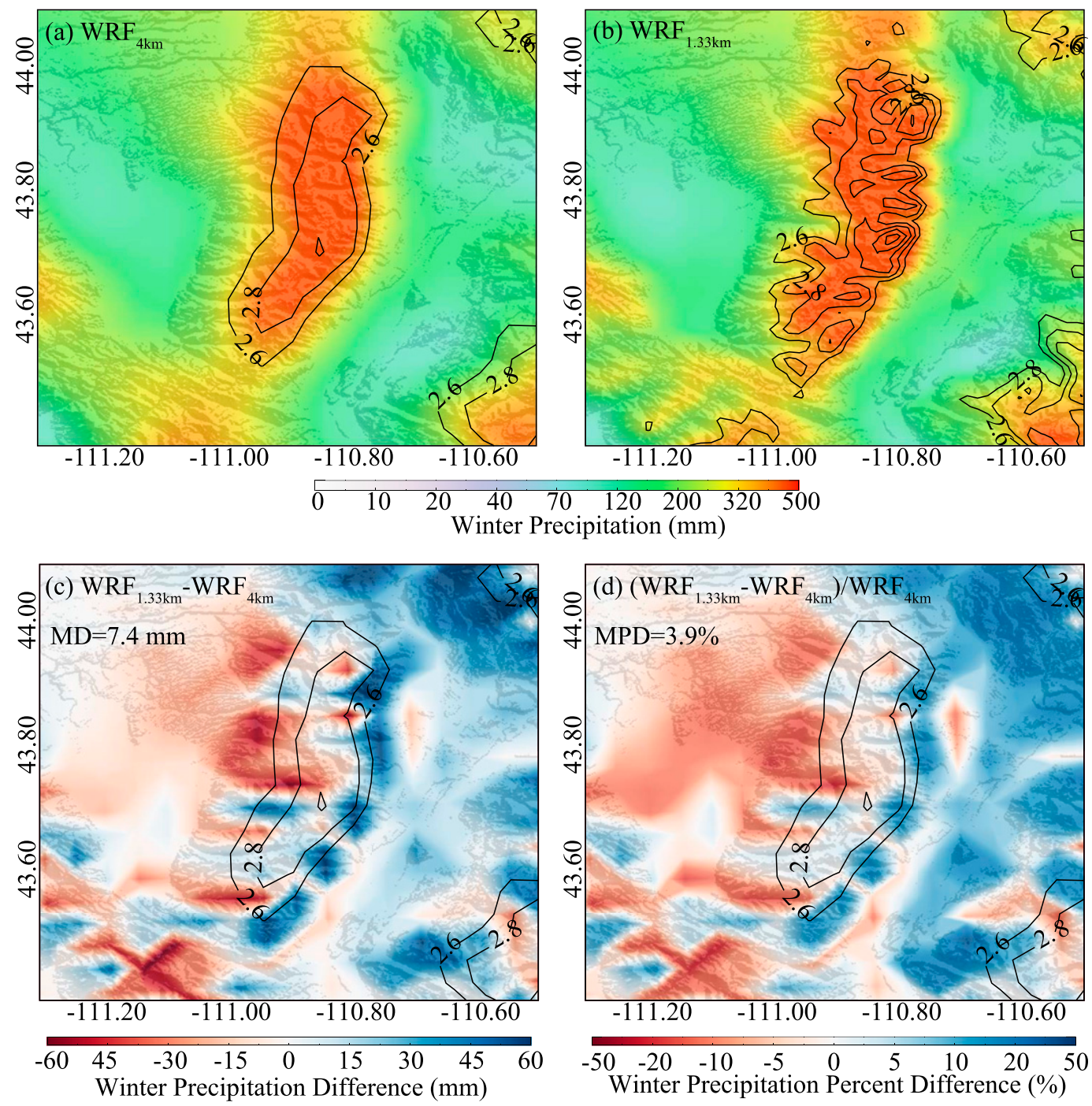

FIG. 2. Ten-year-mean wintertime precipitation maps for the Teton Range from the (a) 4-km-resolution and (b) 1.33-km-resolution simulations. Also shown are the (c) difference and (d) percent difference in the wintertime precipitation between the 1.33- and 4-km-resolution simulations. The mean difference (MD) and mean percent difference (MPD) in the wintertime precipitation are labeled in (c) and (d). The black contours in panels (a), (c), and $(\mathrm{d})$ indicate the terrain height from the 4-km-resolution simulation, and those in (b) give that from the $1.33-\mathrm{km}$-resolution simulation.

Northwest. As we will see below, the same pattern at finer scales is observed in the future-climate IWUS simulation.

\section{b. Future changes in ambient conditions according to the IWUS WRF simulation}

Wintertime orographic precipitation amount and distribution are strongly influenced by the wind field (Colle 2004). Histograms of normalized precipitation are shown in Fig. 4, as a function of the speed and direction of the low-level wind (averaged between the surface and the height of the mountain top). The normalized precipitation is defined as the precipitation amount for different ambient conditions divided by the total precipitation amount, and is calculated for the control and PGW simulations separately. The differences in wind field between the control and PGW simulations are very small (Fig. 4), consistent with the weak wind perturbations imposed in the PGW simulation (Fig. 3). Wintertime winds slightly weaken over the Wind River, Park, and Teton Ranges in the warmed climate.

The precipitation rate is mostly weak in cases with a wind direction parallel to the orientation of mountain crest, and orographic precipitation with winds from the opposite side (from east to northeast) almost never occurs. 

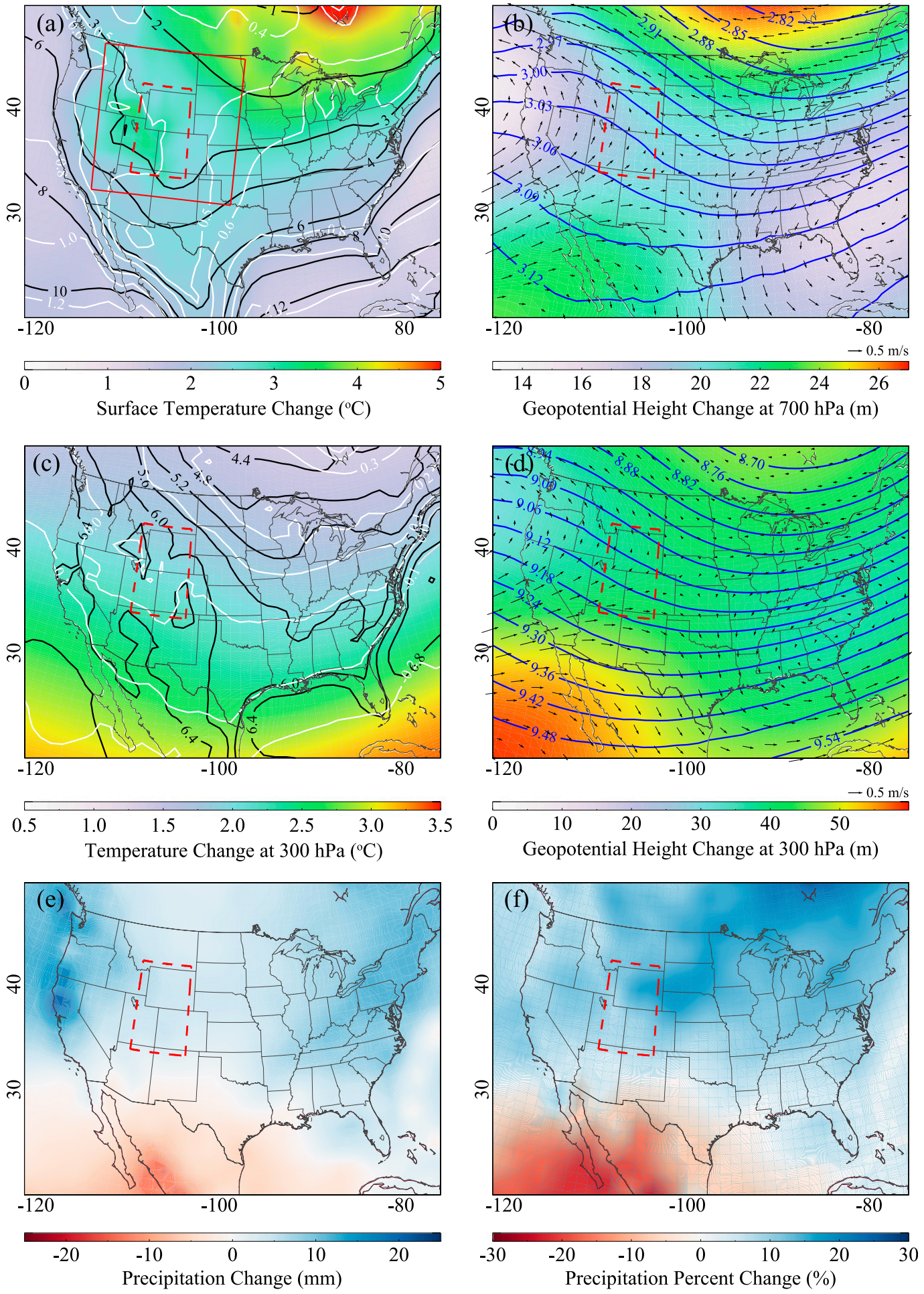

FIG. 3. (a) The 15-GCM ensemble-mean specific humidity near the surface in the current climate ( $\mathrm{g} \mathrm{kg}^{-1}$; black contours), and differences between 1976-2005 and 2035-65 in wintertime temperature (K; colors) and specific humidity (white contours) near the surface. (b) The 15-GCM ensemble-mean geopotential height at $700 \mathrm{hPa}$ in the current climate (km; blue contours), and differences between 1976-2005 and 2035-65 in wintertime geopotential height ( $\mathrm{m}$; colors) and wind (vectors) at $700 \mathrm{hPa}$. (c) As in (a), but for 300-hPa temperature, and lapse rate between the surface and $300 \mathrm{hPa}\left(\mathrm{K} \mathrm{km}^{-1}\right.$; black contours indicate current climate, and white contours indicate the change). (d) As in (b), but for $300 \mathrm{hPa}$. The 15-GCM ensemble-mean (e) absolute and (f) percent differences between 1976-2005 and 2035-65 in wintertime surface precipitation. The red solid line in (a) indicates the RCM domain; the red dashed line in each panel contours the IWUS domain examined here. 
Wind River Range
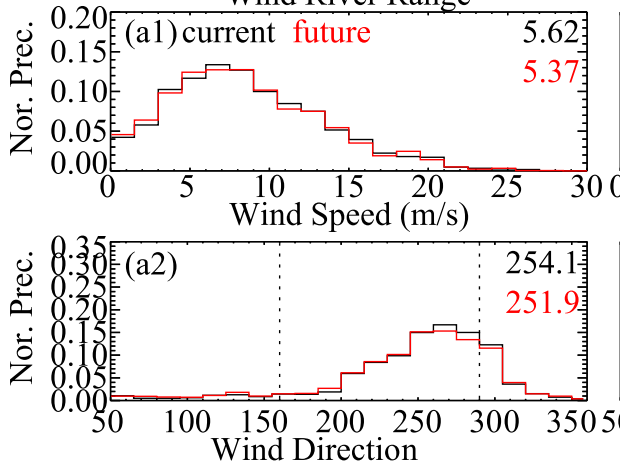

Park Range

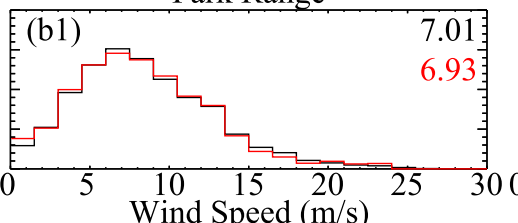

Teton Range

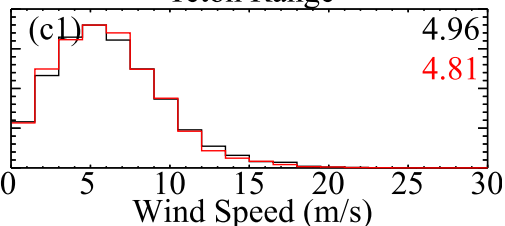

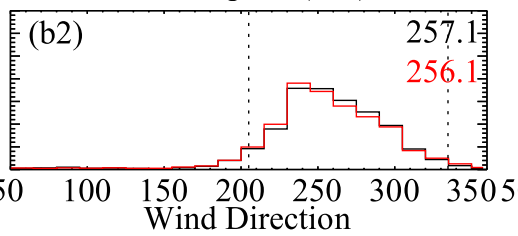

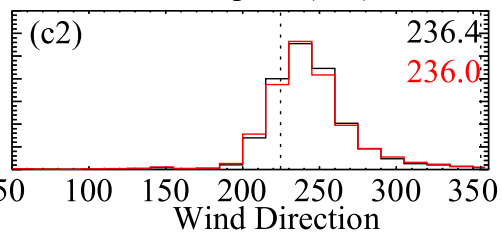

FIG. 4. Histograms of normalized precipitation as function of wind speed and wind direction, from the control and future simulations. The numbers shown are the mean values. The dashed lines in the bottom panels represent the range of wind directions that are used as the threshold in the selection of precipitation events.

Therefore, in the remainder of this study, except where mentioned, only cases with a significant mountainnormal wind component are analyzed. Specifically, suitable wind directions fall between $160^{\circ}$ and $290^{\circ}$, between $205^{\circ}$ and $335^{\circ}$, and between $225^{\circ}$ and $355^{\circ}$ for the Wind River, Park, and Teton Ranges, respectively, as indicated by the dashed lines in Figs. 4a2, $4 \mathrm{~b} 2$, and $4 \mathrm{c} 2$.

The histograms of normalized precipitation as a function of $N^{2}$, Froude number [defined as the ratio of $U$ to the height of the mountain $H$ and $N ; \mathrm{Fr}=U /(N H)]$, CBT, cloud-top temperature (CTT), LCL, and CD for the control and future simulations are shown in Fig. 5. The $N^{2}$, which is averaged from the surface to mountain top, slightly decreases upwind of all three mountain ranges. The Froude number is slightly smaller in the future simulation than in the control simulation for the Park and Teton Ranges but is larger for the Wind River Range. The CBT and CTT increase by approximately $2 \mathrm{~K}$, consistent with the GCM ensemble-mean warming magnitude (Fig. 3). Although the CBT increases in a warmer climate, the $\mathrm{CBH}$ hardly changes (Figs. 5a5,b5,c5) because of the low-level moisture enhancement (Fig. 3). The distributions and mean values of $\mathrm{CD}$ do not significantly change over the three mountain ranges of interest. This is consistent with the cloud liquid/ice water mixing ratio across the three mountain ranges, which show no changes in cloud depth (not shown).

\section{c. Future changes in precipitation distribution}

As indicated in Figs. 6 and 7a, the absolute and percent change in the wintertime precipitation (future minus current) from WRF Model simulations show a widespread increase across IWUS. (All precipitation events are included in Figs. 6 and 7 and not just those with a suitable wind direction.) The absolute increase in wintertime precipitation is higher over mountains than plains, but the percent change is higher over plains than mountains. The areal mean precipitation increase is $11.7 \mathrm{~mm}(14 \%)$ in the IWUS. The precipitation change displays an apparent spatial variability, with an increase of $15.6 \mathrm{~mm}(8.9 \%)$ in mountains above $2500 \mathrm{~m} \mathrm{MSL}$, and $10.6 \mathrm{~mm}(15.4 \%)$ in areas below $2500 \mathrm{~m}$. The precipitation increases by $14.1 \mathrm{~mm}(12.3 \%)$ over the Colorado Rockies, $10.0 \mathrm{~mm}(13.4 \%)$ over the Greater Yellowstone, and $12.9 \mathrm{~mm}(15.2 \%)$ over Wasatch Range, respectively. Over the Wind River, Park, and Teton Ranges above $2600 \mathrm{~m}$, the precipitation increases by $19.4(7.3 \%), 22.5$ $(6.7 \%)$, and $17.9 \mathrm{~mm}(3.8 \%)$, respectively. The mean wind at $1 \mathrm{~km}$ AGL for precipitation events (defined as $>0.1 \mathrm{~mm} \mathrm{~h}^{-1}$, as in Part I), which typically is from the west (black arrows in Fig. 6a), decreases in strength by $\sim 2050$ in the IWUS, including the Wind River, Park, and Teton Ranges. On average, the magnitude of the decrease in mean wind speed is small $\left(<1 \mathrm{~m} \mathrm{~s}^{-1}\right)$, and for the three mountain ranges, the wind speed decreases more in the lee and less on the upwind side (red arrows in Fig. 6).

Consistent with the lower relative increase in winter precipitation over mountains than plains is the decrease in total hours of precipitation over mountains in a warmer climate (Fig. 7b). Such decrease is due to fewer light precipitation events; moderate and heavy precipitation events actually become more frequent in a warmer climate (shown later). The decrease in light precipitation events is consistent with the decrease in cross-mountain wind speed, either defined as the mean wind speed (Fig. 6) or the prevailing wind speed in winter storms (Fig. 7a). Herein the prevailing wind in winter storms is defined as the precipitation-weighted wind at $1 \mathrm{~km}$ AGL (Jing et al. 2017). In fact, almost all very light or light precipitation events that are present in the current climate but disappear in the PGW simulation experience a cross-mountain wind speed reduction, over the three 

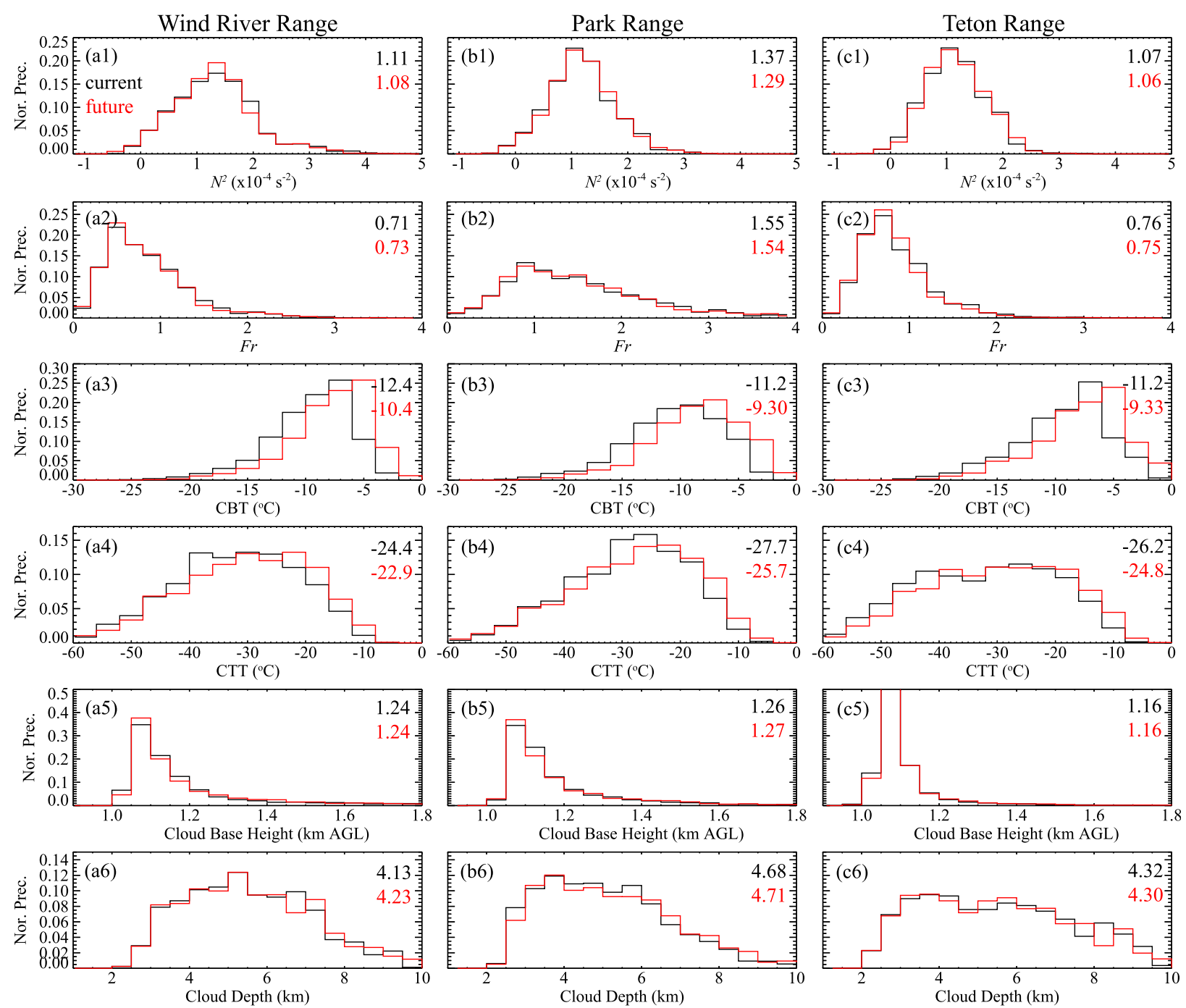

FIG. 5. Histograms of normalized precipitation as functions of $N^{2}$, Fr, CBT, CTT, CBH, and CD. The numbers shown are the mean values.

mountain ranges of interest. However, other factors may also influence the precipitation frequency. For example, the same very light/light precipitation events "disappearing" in the PGW simulation experience mostly low-level clouds of limited depth, and on average their cloud depth decreases further in a warmer climate, over all three mountain ranges. An increase in lower-tropospheric temperature and CBT (as indeed predicted by the GCMs) may also decrease the prevalence of orographic clouds in the dendritic growth region where growth by vapor deposition is rapid (Kirshbaum and Smith 2008).

The PGW technique implies that individual storms observed in the current climate recur in the future climate, albeit perturbed by the climate change signal. The population of precipitation events $\left(>0.1 \mathrm{~mm} \mathrm{~h}^{-1}\right)$ over individual mountain ranges may change however: some light precipitation events, in which the cross-mountain wind speed is typically weak, may occur in the current climate but disappear in the future climate because of the weaker upstream water vapor flux. On the other hand, moderate and heavy precipitation events, in which cross-mountain wind is typically stronger, will not disappear, notwithstanding the small weakening of cross-mountain wind. The relative increase of mean precipitation rate is similar over mountains and plains (Fig. 7c), so changes in precipitation rate cannot explain the lower relative increase in total wintertime precipitation over mountains than plains (Fig. 7a).

The wintertime precipitation typically exhibits little change on the east side, which usually is the lee side (Figs. 6 and 7a), for most of the mountains in the IWUS, such as the Wind River and Park Ranges. However, the relative humidity at $1 \mathrm{~km}$ AGL (as well as other levels) increases in the lee of mountain ranges (Fig. 7d). 

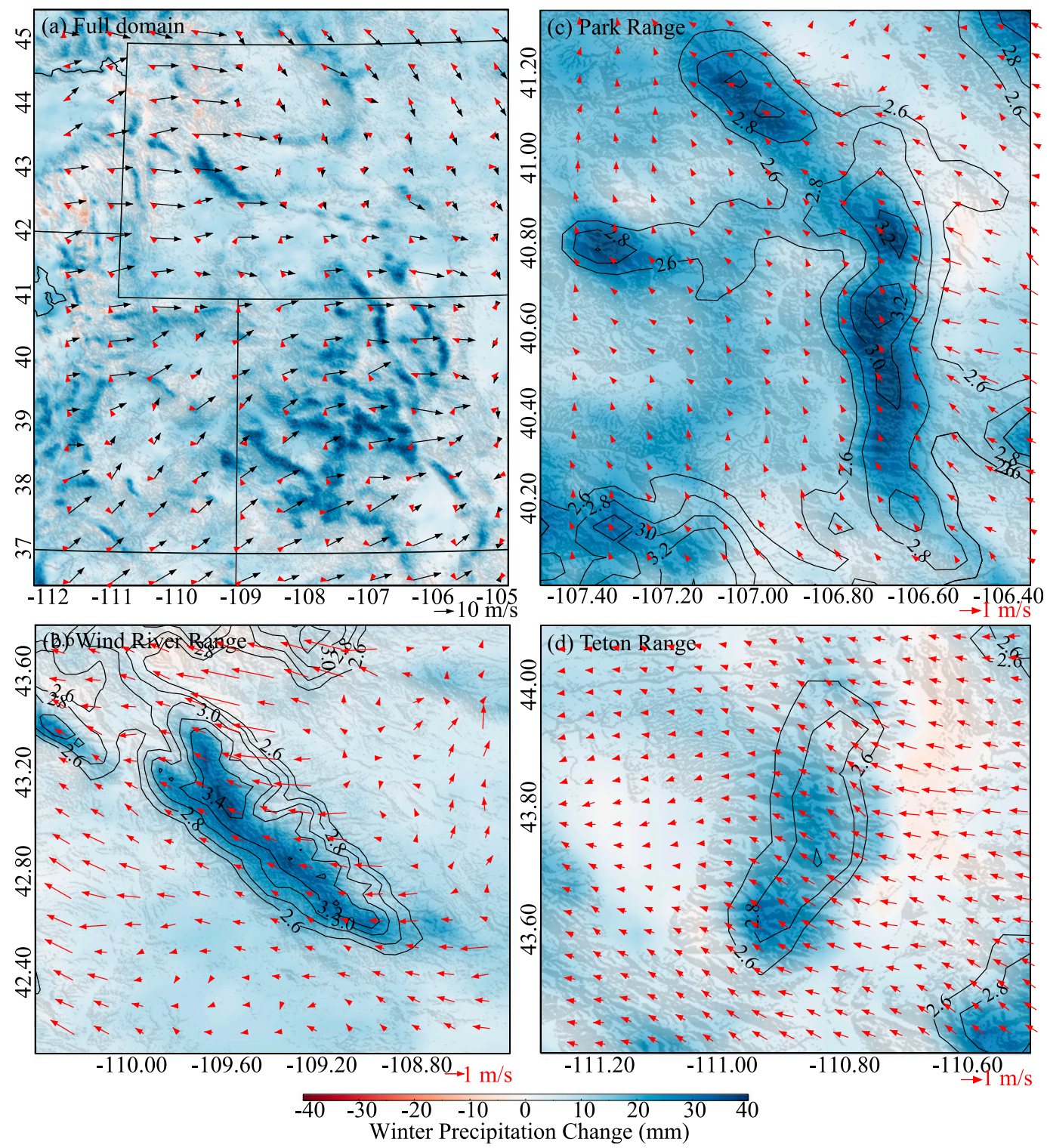

FIG. 6. The absolute change in wintertime precipitation over the (a) full domain, (b) Wind River Range, (c) Park Range and (d) Teton Range. The terrain height contours are shown in (b)-(d). The black vectors indicate the mean wind at $1 \mathrm{~km}$ AGL for precipitation events, and the red vectors indicate the change (future minus current) in the mean wind at $1 \mathrm{~km}$ AGL for precipitation events.

This may be due to a reduced strength of the leeside subsidence and drying, associated with the reduced crossmountain wind speed. It may be due also to an increased frequency of "upslope" events (with low-level wind from the east/northwest) in winter in a warmer climate (Fig. 6). Over the Wind River Range (Fig. 6b), for instance, in $15 \%$ of the light precipitation events the low-level wind changes from positive crosswind (southwesterly component) to negative crosswind (northeasterly component). Such shift is typically due to stronger Colorado lee cyclogenesis. Such cyclogenesis and upslope storms are more common in spring, producing much precipitation. A more detailed study is required to better understand the increased relative humidity on the east side of IWUS mountains in winter.

The increase in the wintertime precipitation over the three mountain ranges is due to an increase in precipitation rate rather than in precipitation frequency. The mean precipitation rate increases by $0.07,0.08$, and $0.08 \mathrm{~mm} \mathrm{~h}^{-1}$ over the Wind River, Park, and Teton Ranges, respectively. Heavy precipitation events become more common in a warmer climate $(35 \%$ increase 

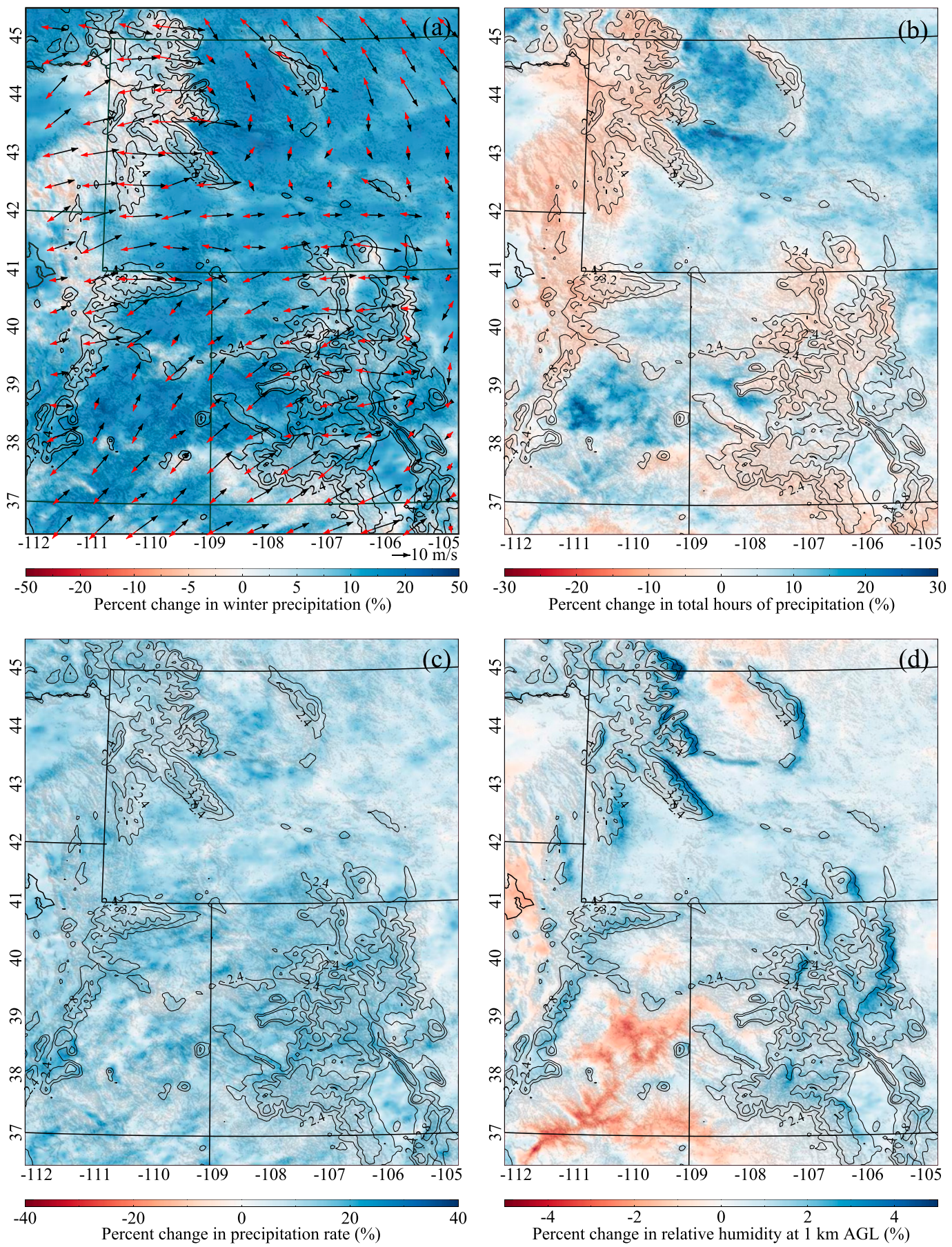

FIG. 7. (a) Percent change in wintertime precipitation. The black vectors indicate the prevailing wind at $1 \mathrm{~km}$ AGL under the current climate, and the red vectors indicate the change (future minus current) in the prevailing wind at $1 \mathrm{~km}$ AGL. (b) Percent change in total hours of wintertime precipitation. (c) Percent change in wintertime precipitation rate. (d) Percent change in wintertime relative humidity at $1 \mathrm{~km}$ AGL.

in frequency), as shown by the histograms in Fig. 8, which includes all precipitation events in all wind directions. The fraction of precipitation considered to be "heavy" $\left(>2.5 \mathrm{~mm} \mathrm{~h}^{-1}\right)$ increases by $3 \%, 5 \%$, and $5 \%$ over the Wind River, Park, and Teton Ranges, respectively, and that considered to be "light" $\left(0.1-1.0 \mathrm{~mm} \mathrm{~h}^{-1}\right)$ decreases correspondingly ( $13 \%$ decrease in frequency). The vertical distributions of the climatic change in vertical 

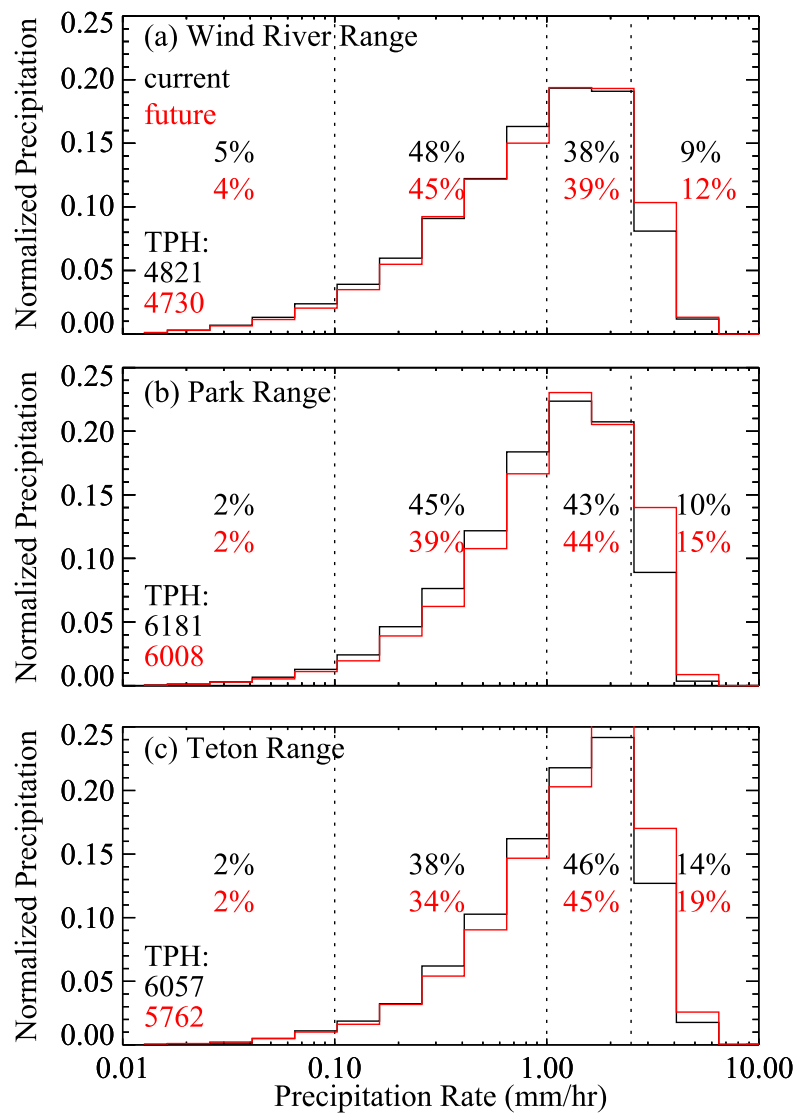

FIG. 8. Histograms of the normalized precipitation at elevations above $2.6 \mathrm{~km}$ as a function of precipitation rate for the (a) Wind River Range, (b) Park Range, and (c) Teton Range for the control and future WRF simulations. The dashed lines represent the precipitation rates of $0.1,1$, and $2.5 \mathrm{~mm} \mathrm{~h}^{-1}$. The percentiles of the precipitation from very light $\left(<0.1 \mathrm{~mm} \mathrm{~h}^{-1}\right)$, light $\left(0.1-1.0 \mathrm{~mm} \mathrm{~h}^{-1}\right)$, moderate $\left(1.0-2.5 \mathrm{~mm} \mathrm{~h}^{-1}\right)$, and heavy $\left(>2.5 \mathrm{~mm} \mathrm{~h}^{-1}\right)$ precipitation events are shown, as is the total precipitation hours (TPH; $\geq 0.1 \mathrm{~mm} \mathrm{~h}^{-1}$ ) for the three mountain ranges.

water vapor flux and in hydrometeor (snow + rain + graupel) mixing ratio across the mountain ranges (Figs. 9b,d,f) are very similar to the distributions of vertical water vapor flux and of hydrometeor mixing ratio themselves (Fig. 10 in Part I), since the flow patterns in winter storms hardly change under the PGW assumptions. The increase in vertically integrated vapor flux, about $17 \%$, is consistent with the estimate by Eidhammer et al. (2018) over the Colorado Rockies $\left(9 \% \mathrm{~K}^{-1}\right.$ of warming).

Thus, the precipitation distribution across the mountain ranges does not change significantly in a warmer climate. Slightly more additional precipitation falls on the upwind slopes of the Wind River Range compared to the lee side. The absolute increase in wintertime precipitation rate is the highest over mountain crests, and is relatively higher on the upwind side than the lee side (Figs. 9a,c,e).
The increased vertical moisture flux is associated with higher cloud-base specific humidity, instead of stronger cross-mountain wind or updraft. Note that in Fig. 9 only the precipitation events for the given wind directions shown in Fig. 4 are included. (The transects for all wintertime precipitation events show very similar results.)

The low-level cross-mountain winds weaken slightly (less than $1 \mathrm{~m} \mathrm{~s}^{-1}$ ) on the upwind side and over the crest. The leeside winds are much stronger than on the upwind side (Figs. 7, 10, or 12 in Part I) in the current climate, on account of downslope acceleration, especially when the upstream flow is blocked. In a warmer climate, such downslope accelerations become less common and weaker, implying upslope wind anomalies on the lee side, especially for the Wind River Range (Figs. 9b,d,f). This explains why the increase in hydrometeor mixing ratio is confined to the upwind side, and why most additional precipitation falls near the crest. Precipitation phase (rain versus snow, with different fall speeds) may affect the changes in precipitation distribution across a crest (Zängl 2008; Yuter et al. 2011). However over the mountain ranges considered here, virtually all wintertime precipitation ( $>99 \%$ above $2500 \mathrm{~m}$ MSL) falls as snow, rather than rain, even in the warmed climate.

\section{d. Ambient factors controlling the changes in precipitation distribution}

The analysis above shows that in a warmer climate light winter snowfall becomes less common, and it is the increase in precipitation rate that results in more seasonal precipitation. To investigate the ambient factor(s) dominating the precipitation changes, we use the statistical equations of precipitation rate and UPF as functions of ambient factors developed in Part I. For now we use RCM output; the use of GCM output is explored later. In Part I, the mountain-average precipitation rate $P$ was expressed as a function of $\mathrm{CD}, U, \mathrm{CBT}$, and $\mathrm{LCL}$, and the UPF was expressed as a function of $U, \mathrm{LCL}, \mathrm{CBT}$, $\mathrm{CD}$, and $N^{2}$ :

$$
\begin{aligned}
P= & \exp \left(a_{0} \mathrm{CD}^{a_{1}}+a_{2}\right)+\left(a_{3} \mathrm{CD}+a_{4}\right) U \\
& +\left(a_{5} \mathrm{CD}+a_{6}\right) \mathrm{CBT} \\
& +\left(a_{7} \mathrm{CD}+a_{8}\right) \mathrm{LCL}+a_{9} \text { and } \\
\mathrm{UPF}= & \exp \left(b_{0} U^{a_{1}}+b_{2}\right)+\left(b_{3} U+b_{4}\right) \mathrm{LCL} \\
& +\left(b_{5} U+b_{6}\right) \mathrm{CBT}+\left(b_{7} U+b_{8}\right) \mathrm{CD} \\
& +\left(b_{9} U+b_{10}\right) N^{2}+b_{11},
\end{aligned}
$$

where $P$ is the mean precipitation rate and $a_{0}-a_{9}$ and $b_{0}-b_{11}$ are fitted constant coefficients for specific mountain ranges. For the Wind River and Park Ranges, 
Wind River Range
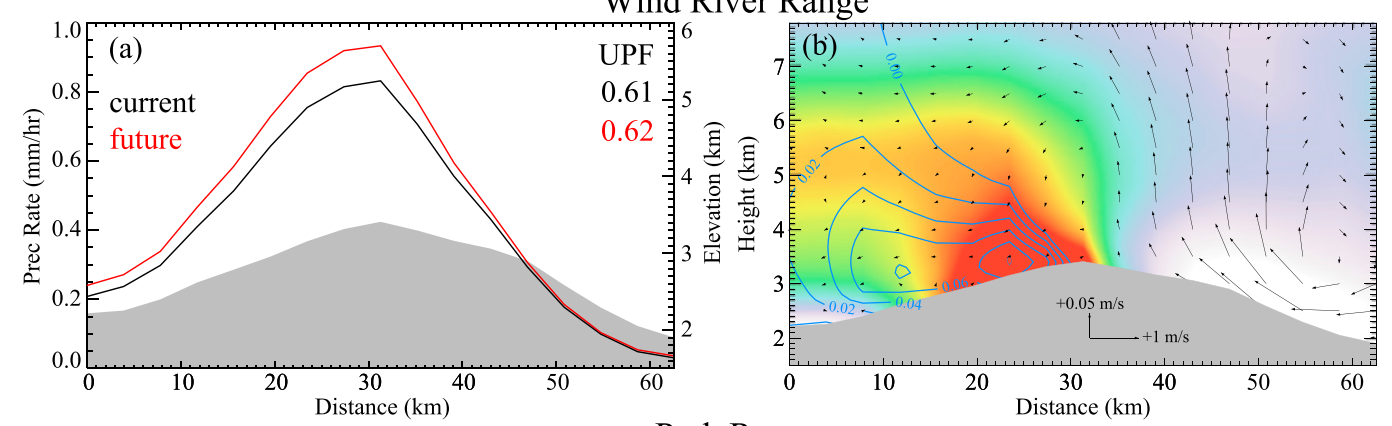

Park Range
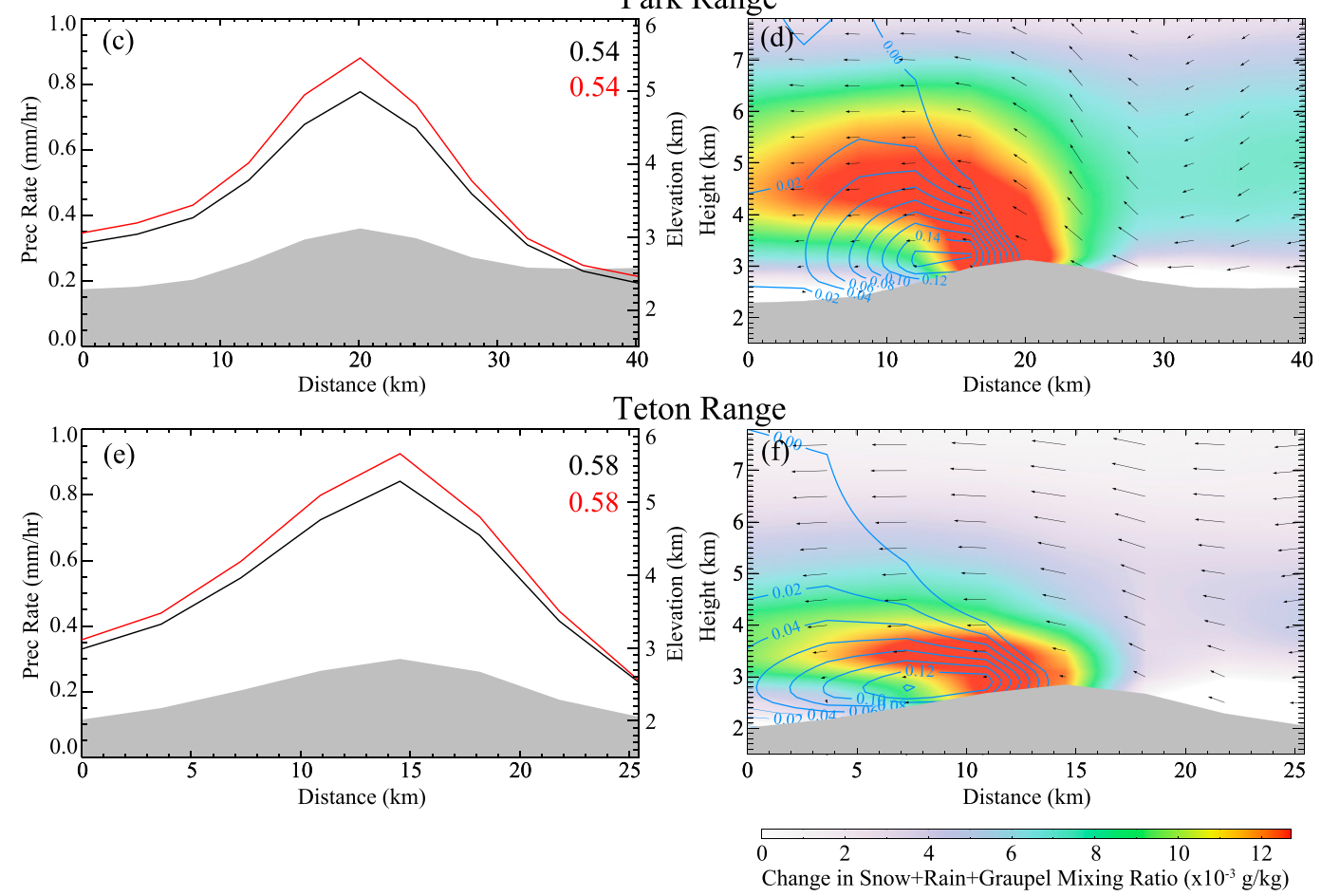

FIG. 9. Cross sections of (left) wintertime precipitation rate, and (right) changes (future minus current) in wintertime hydrometeor mixing ratio (colors), vertical vapor flux $\left(\mathrm{g} \mathrm{s}^{-1} \mathrm{~m}^{-2}\right.$; blue contours, positive only), and wind vectors over the (a),(b) Wind River, (c),(d) Park, and (e),(f) Teton Ranges.

the values of these coefficients can be found in Tables 1 and 2 in Part I, and for the Teton Range they are shown in Tables 2 and 3. The coefficients for the Teton Range that were developed in Part I are not used here because of the different model resolutions $(4 \mathrm{~km}$ here and $1.33 \mathrm{~km}$ in Part I). The statistical equations work well for both the current and future climate simulations, as evinced in the scatterplots of statistically fitted versus
IWUS-simulated precipitation rate and UPF (Fig. 10). The differences between the fitted and IWUS-simulated precipitation rate and UPF are mostly within a factor of 2 , and the correlation coefficients are all higher than 0.7.

At hourly time scales, there is a relatively large dispersion between the fitted and IWUS-simulated precipitation rate and UPF, but the averages agree very well. The monthly mean changes in the precipitation

TABLE 2. Fitted coefficients in Eq. (2) for the precipitation rate and UPF over the Teton Range from the historical 4-km-resolution simulation.

\begin{tabular}{|c|c|c|c|c|c|c|c|c|c|}
\hline$a_{0}$ & $a_{1}$ & $a_{2}$ & $a_{3}$ & $a_{4}$ & $a_{5}$ & $a_{6}$ & $a_{7}$ & $a_{8}$ & $a_{9}$ \\
\hline $1.74 \times 10^{-4}$ & $5.53 \times 10^{-1}$ & 4.37 & $5.29 \times 10^{-6}$ & $4.11 \times 10^{-2}$ & $1.21 \times 10^{-6}$ & $2.47 \times 10^{-2}$ & $-3.52 \times 10^{-7}$ & $3.72 \times 10^{-4}$ & -86.6 \\
\hline
\end{tabular}


rate and UPF (future minus current) predicted by the statistical equations versus the IWUS WRF data are shown in Fig. 11 for the three mountain ranges. The fitted and modeled values are mostly along the 1:1 line, with fairly high correlations $(>0.6)$. The overall average changes in wintertime precipitation rate and UPF from the statistical equations are in good agreement with WRF simulations, as shown by the colored circles in Fig. 11. Therefore, the statistical equations can be used to predict changes in wintertime precipitation rate and distribution across mountain ranges using GCM output that does not resolve the individual mountains but does resolve the ambient factors.

Note that, in Eqs. (2) and (3), changes in terms of wind speed, stability, and cloud properties are considered. These factors are highly dependent on the behavior of extratropical storms (track, intensity, frequency) and low-frequency climate variability, which are assumed to remain unchanged in the PGW technique. This study focuses on the impact of changes that are captured by the PGW approach, which include changes in the monthly-mean position and intensity of the jet stream, but mostly covers thermodynamics (temperature and moisture changes). Although low-frequency climate variability is more uncertain, it may be significant (e.g., Bender et al. 2012; Shi and Durran 2014) and result in larger changes in wind speed, stability, and cloud properties than suggested by the PGW approach. Nevertheless, the statistical downscaling equations developed herein, relating ambient factors to precipitation distribution across specific mountain ranges in the IWUS, can be used with the output from any GCM. These equations remain valid, even when such models are improved and better capture internal climate variability.

The mean changes in precipitation rate and UPF caused by different factors are shown in Fig. 12. The blue stars are estimated from hourly changes in different factors; only the precipitation events occurring in both the current and future climate are included, that is, about $90 \%$ of all precipitation events in either climate. The black stars are the changes predicted by the mean monthly changes in individual ambient factors $(\mathrm{CD}$, wind speed, $\mathrm{CBH}$, and temperature) in each climate. The red stars indicate the actual change from the IWUS WRF simulations. The increase in the wintertime precipitation rate is largely explained by the increase in CBT over the Wind River Range, that is, the increase in both low-level temperature and specific humidity (Figs. 12a,c,e). For the Park and Teton Ranges, the RCM-predicted changes in UPF are nearly 0; the overestimation by the fitted UPF is mostly due to the uncertainty from $U$ and LCL. Therefore, this statistical method cannot precisely predict the small UPF change, 

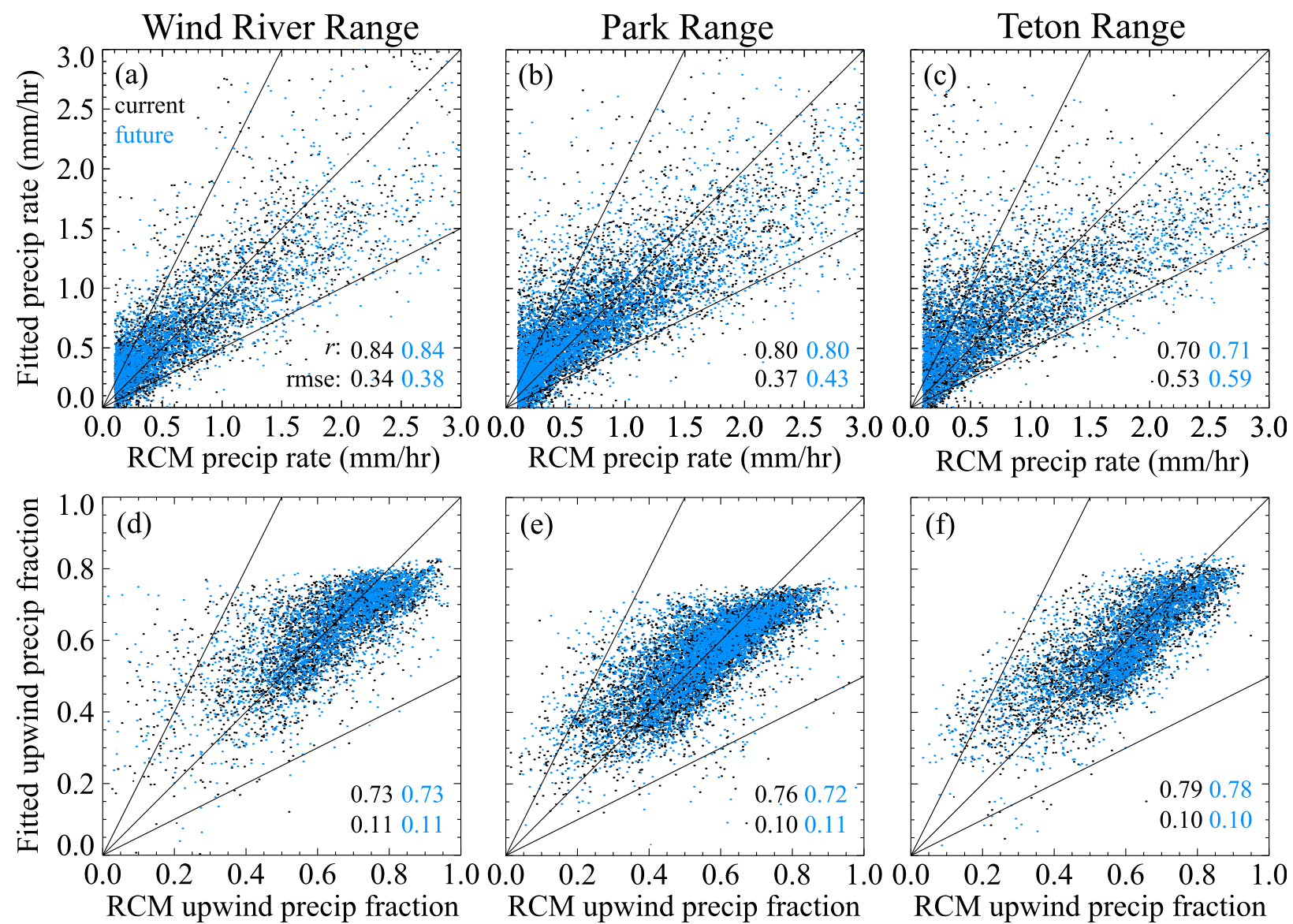

FIG. 10. Scatterplots of the fitted and WRF (top) hourly precipitation rate and (bottom) UPF over the (a),(d) Wind River, (b),(e) Park, and (c),(f) Teton Ranges. The black and blue dots represent the current and future values, respectively. The black solid lines are the 1:1 line and factor-of-2 lines. The correlation coefficient $r$ and root-mean-square-error (rmse) are shown.

which is smaller than $1 \%$. Other factors have a minor impact on the change in precipitation rate.

Although the frequency of light precipitation events decreases in a warmer climate, its impact on the mean precipitation rate is minor. The UPF increases very slightly $(<\sim 1 \%)$ over the three mountain ranges (Figs. 9 and $12 \mathrm{~b}, \mathrm{~d}, \mathrm{f})$, and the changes in LCL and CBT have opposite impact on the changes in UPF. The composite changes in precipitation rate and UPF based on the hourly changes in different factors (blue stars) generally agree with the estimate from the 10-winter-mean changes in different factors (black stars). Therefore, if no hourly data are available for the ambient conditions, the monthly mean values of these ambient conditions can be used (e.g., from GCM output) to estimate changes in wintertime orographic precipitation rate and distribution.

There is a wide diversity in mean changes in the wintertime ambient conditions by the year $\sim 2050$ predicted by the 15 different GCM ensemble members (Fig. 13). While the IWUS WRF simulation (based on changes in the ensemble mean) predicts a decrease of cross-mountain wind speed $U$ over the three mountains of interest during precipitation events (Figs. 4, 6, and 7a), the GCM ensemble-mean changes shown in Fig. 3 and Fig. 13 (averaged over all times and not just precipitating times) are near zero. Some of the ensemble members show a relatively substantial change in $U$ $\left( \pm 0.6 \mathrm{~m} \mathrm{~s}^{-1}\right.$; Fig. 13). Similarly, individual members disagree on changes in low-level stability $( \pm 1 \times$ $\left.10^{-5} \mathrm{~s}^{-2}\right), \mathrm{CBH}( \pm 100 \mathrm{~m})$, and CBT $( \pm 1 \mathrm{~K})$. Cloud depth is not presented because the coarse vertical resolution in GCMs cannot properly represent the actual subtle change. In addition, to obtain a statistically meaningful change in CD, hourly GCM data would need to be available rather than the monthly mean values used here. Fortunately, CD is a minor contributing factor to the orographic precipitation changes (Fig. 12). In general, the mean changes shown in Fig. 13 are consistent with the changes shown in Figs. 4 and 5 in magnitude. 

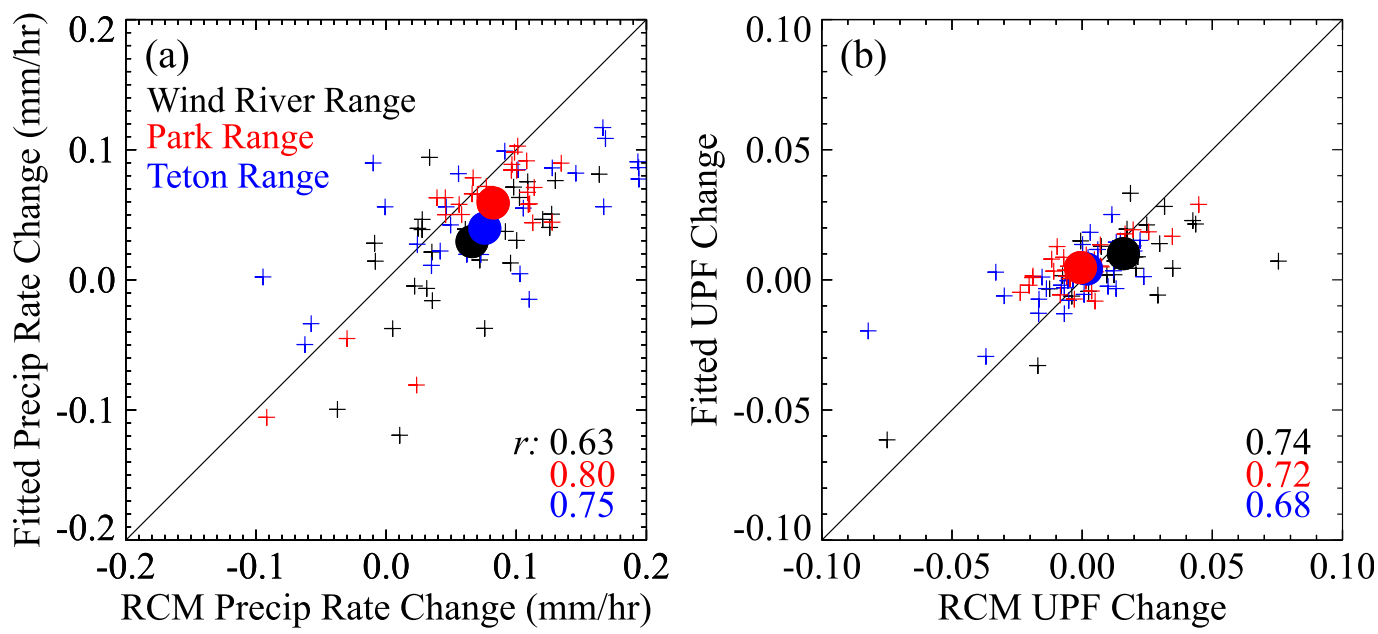

FIG. 11. Fitted vs WRF monthly (plus signs) and average (dots) differences (future minus control) in (a) wintertime precipitation rate and (b) UPF over the Wind River, Park, and Teton Ranges. Values of $r$ are shown for each of the three ranges.

We now estimate the precipitation rate and UPF changes by applying the statistical relations in Eqs. (2) and (3) to the above GCM-derived ambient conditions. The statistically estimated changes in the wintertime precipitation rate and UPF have large spread among the 15 GCM members (Fig. 14), in accordance with the large uncertainties in the predicted changes in ambient conditions that are critical to wintertime orographic precipitation in IWUS. The actual uncertainty could be even larger due to the neglect of future circulation/storm changes in the PGW approach. The mean estimated change in wintertime orographic precipitation rate is $0.049-0.065 \mathrm{~mm} \mathrm{~h}^{-1}$ for the three mountains of interest (Table 4). This is slightly lower than the WRF-predicted mean change of $0.07-0.08 \mathrm{~mm} \mathrm{~h}^{-1}$. The standard deviations among the ensemble members have nearly the same magnitude, indicating a small probability that the orographic precipitation will decrease according to CMIP5 guidance (ranging from $9 \%$ in the Teton Range to $14 \%$ in the Park Range). The increase in CBT has the most contribution to the enhanced mean precipitation rate. The mean change in UPF is very small-smaller than the variation among the ensemble members.

\section{Discussion}

This study investigates the changes in wintertime orographic precipitation enhancement and cross-barrier precipitation distribution in the IWUS in a warmer climate, on the basis of high-resolution convection-permitting WRF regional climate simulations. Climate change is driven by the CMIP5 ensemble-mean changes along the model boundaries using the PGW technique. It is shown that light precipitation becomes less frequent in a warmer climate, at least partially due to the weakening of the lowlevel cross-mountain wind. The mean precipitation rate increases over mountain ranges mainly in association with the increased temperature and enhanced atmospheric moisture. Because the robustness of these findings depends on the reliability of the driver climate prediction (a question that is beyond the scope of this study), statistical relationships that relate (GCM resolved) upwind ambient conditions to finescale orographic precipitation are applied to assess the uncertainty of predicted orographic precipitation changes that results from the inter-GCM variability. It is found that most of the 15 members predict an increase in wintertime precipitation over the Wind River, Park and Teton Ranges (Fig. 14), as in the WRF downscaling. The statistical approach is computationally economic and provides an alternative for assessing finescale orographic precipitation changes from GCM predictions. Note that although these relationships are specific to individual mountains, the technique can be applied elsewhere.

The statistical relationships also reveal the relative contribution and importance of various ambient and cloud conditions to the WRF-downscaled orographic precipitation changes. The increase in atmospheric moisture in a warmer climate accounts for most of the simulated increase of precipitation rate over the Wind River, Park, and Teton Ranges. The moisture flux increases, notwithstanding the slight weakening of cross-mountain winds. The UPF increases only slightly, attributed mainly to an increase in atmospheric moisture.

We place this study, which is geographically somewhat specific, in the context of recent work that considers 

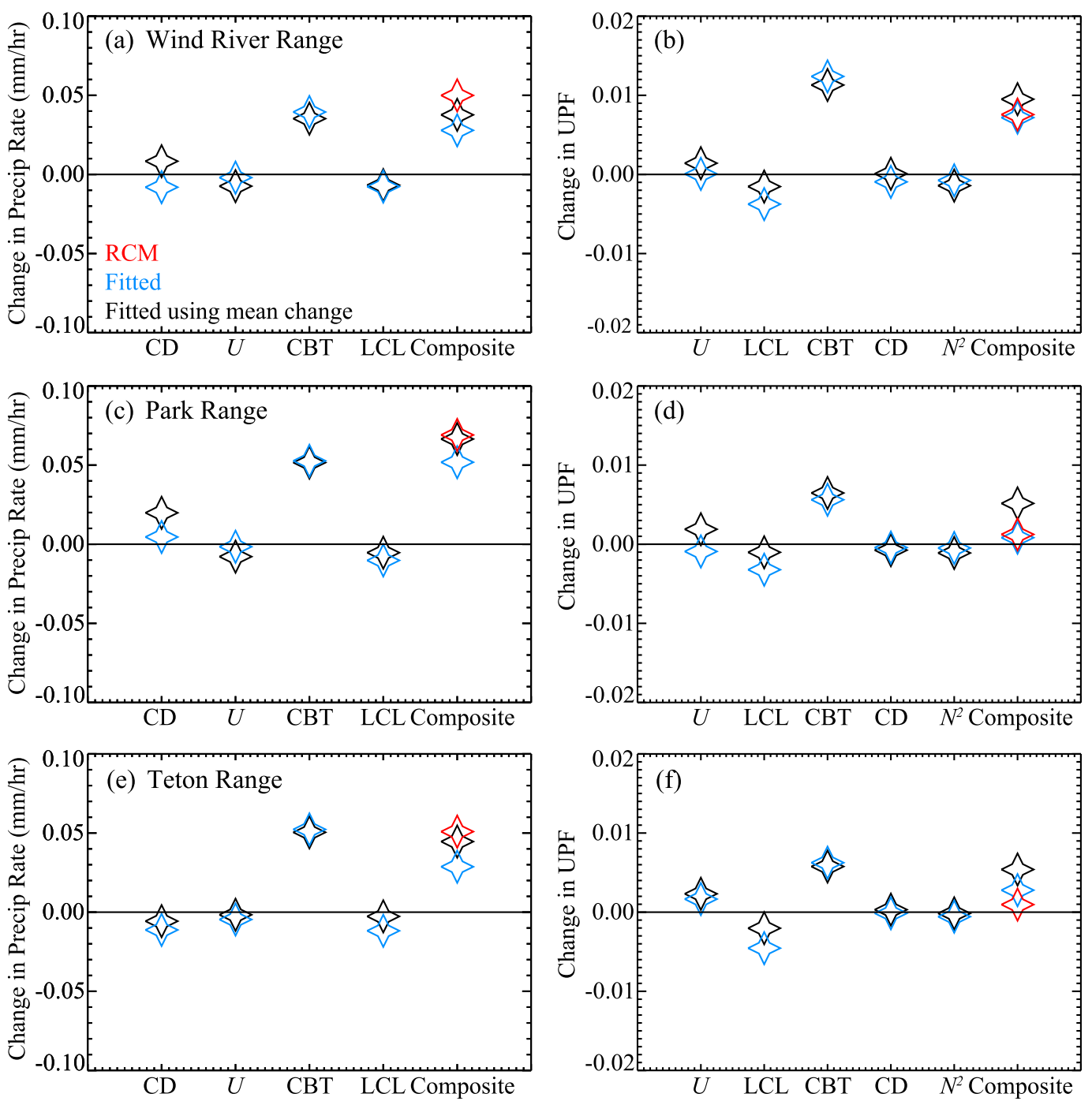

FIG. 12. Changes in wintertime (left) precipitation rate and (right) UPF predicted by different ambient factor(s). The blue stars are estimated from hourly changes in different factors, and only the precipitation events that occur in both the control and future simulations are included. The black stars are estimated from the wintertime monthly mean changes in different factors, with all precipitation events in the control simulation included. The red stars indicate the results from WRF simulations.

midlatitude orographic precipitation more generally. Using an idealized simulation, Siler and Roe (2014) found an upward shift of LCL with warming, leading to a shift in precipitation toward the lee, that is, a decrease in UPF. Yet our study does not find a significant change in $\mathrm{CBH}$ or in UPF in winter storms in a warmer climate, for the three mountain ranges investigated here. Kirshbaum and Smith (2008) also use idealized model simulations to show that the drying ratio (DR), which is defined as the fraction of the impinging water vapor that is removed by precipitation (the ratio of precipitation to incoming vapor flux), decreases in a warming climate due to the reduced normalized condensation rate and the gradual replacement of the more efficient mixed-phase precipitation growth with the warm-rain process. Consistent with our work, Eidhammer et al. (2018) used RCM simulations with a similar PGW approach over the IWUS region, and also found cold-season precipitation to increase in a warming climate, by about $6 \% \mathrm{~K}^{-1}$, and proportionally more over the plains than the mountains. Consistent with Kirshbaum and Smith (2008), they found a decrease in efficiency of orographic precipitation in a warmer climate, and a decline in DR, especially over wider mountain ranges, which they partially attribute to a reduction in crossmountain wind speed during winter storms. In this study, 


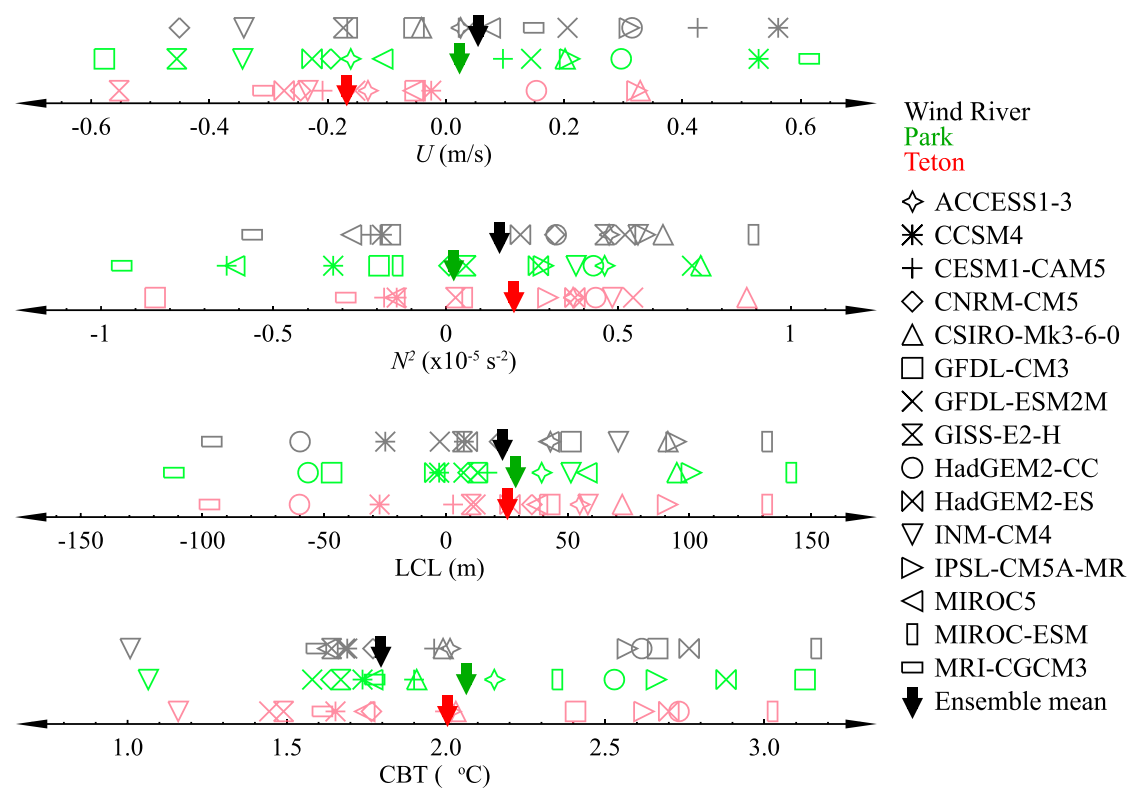

FIG. 13. Changes in $U, N^{2}$, LCL, and CBT (future minus current) predicted by the 15 CMIP5 GCMs for the Wind River, Park, and Teton Ranges.

we further showed the less increase in precipitation amount over mountains than plains is due to the reduced light precipitation frequency rather than intensity.

The dominant factor or factors that control the future changes in wintertime precipitation may vary geographically. For example, over the Cascade Range in the northwestern United States, the low-level westerly cross-mountain wind is predicted to weaken more substantially, by up to $1-2 \mathrm{~m} \mathrm{~s}^{-1}$, (Fig. 3). The resultant weakening of orographic enhancement may overtake the impact of water vapor increase, leading to precipitation reduction. Interestingly, the long-term historical snow gauge record already documents a declining trend in precipitation over the Cascade Range, attendant with decreasing cross-mountain wind in winter storms (Luce et al. 2013). However, the CMIP5 ensemble mean predicts that the wintertime precipitation will increase over the Cascade Range in a warmer climate (Fig. 3; see also Liu et al. 2017), possibly indicative of the predominant impact of increasing atmospheric moisture over decreasing wind speed. The Coastal Range and Sierra Nevada in the northern California, on the other hand, are expected to experience strengthened low-level cross-mountain (southwesterly) wind by $\sim 2050$. Therefore, the predicted substantial increase in wintertime orographic precipitation over these ranges (Fig. 3) may be due more water vapor and stronger cross-mountain winds, both contributing to an increase in moisture flux.

The PGW approach certainly has limitations. One oft-cited limitation is that, while the mean intensity and location of the polar jet can change, baroclinic systems follow essentially the same track at the same frequency and similar intensity in the future climate, since changes are applied to the driver reanalysis data only on a monthly mean basis (Rasmussen et al. 2014). This situation may be partially responsible for the abovediscussed differential precipitation changes between WRF simulations and CMIP5 models. By the same token, low-frequency variability and teleconnection patterns are implicitly assumed to remain unchanged. The statistical downscaling equations developed herein for specific IWUS mountain ranges remain valid for any GCM output, however, and thus this technique serves as a suitable alternative approach to computationally more expensive approaches, such as a variable-resolution GCM with regional refinement over the area of interest (e.g., Wu et al. 2018). This study focuses on the impact of ambient changes resulting from 50 years of global warming (as indicated by the CMIP5 ensemble mean under the $\mathrm{RCP} 8.5$ emission scenario) on orographic precipitation in the IWUS region. To a first order, these are thermodynamic changes, and the outcome is deterministic. But we also examine uncertainty, and the potentially important impact of changes in large-scale circulation, by applying the statistical equations to the various CMIP5 members.

\section{Conclusions}

Convection-permitting WRF simulations described in Wang et al. (2018) are used to study changes in wintertime precipitation across mountain ranges in the IWUS in a warming climate. The climate perturbations between 

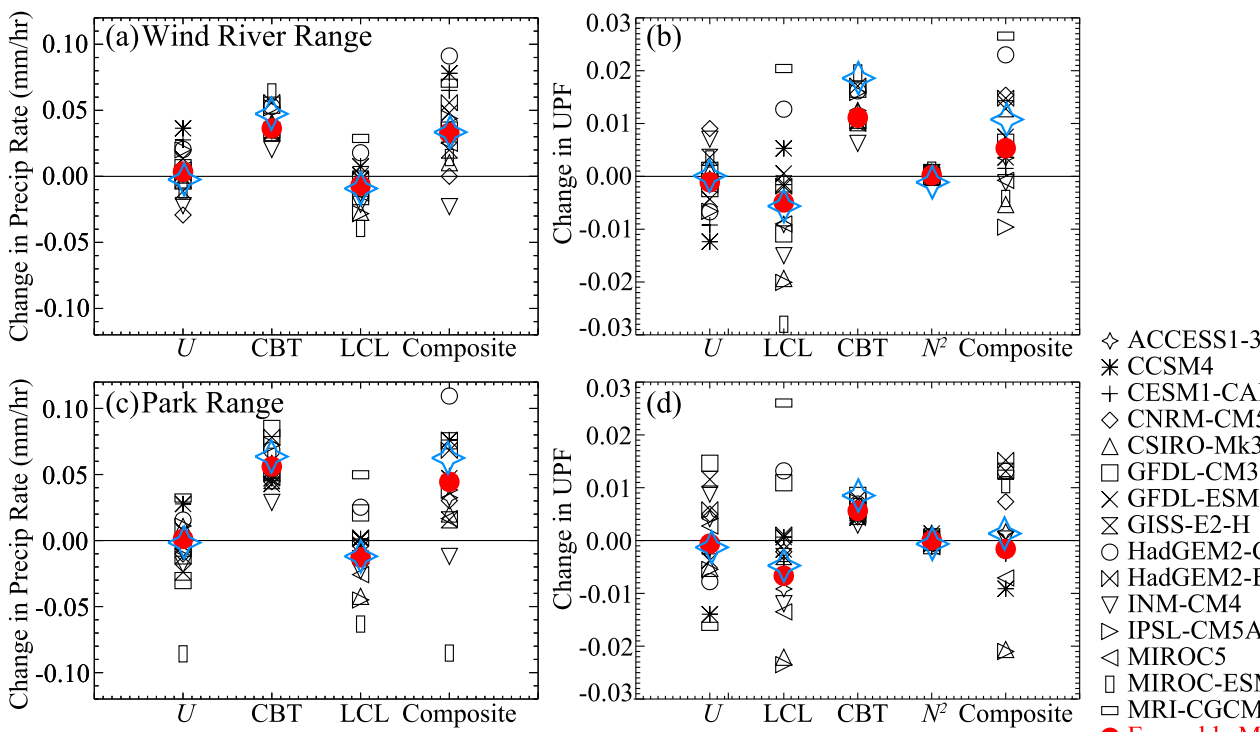

\section{* CCSM4}

$\diamond$ CNRM-CM5

$\triangle$ CSIRO-Mk3-6-0

$\square$ GFDL-CM3

$\times$ GFDL-ESM2M

$\triangle$ GISS-E2-H

O HadGEM2-CC

$\bowtie$ HadGEM2-ES

$\nabla$ INM-CM4

$\triangleright$ IPSL-CM5A-MR

$\triangleright$ IPSL-CM

MIROC-ESM

$\square$ MRI-CGCM3
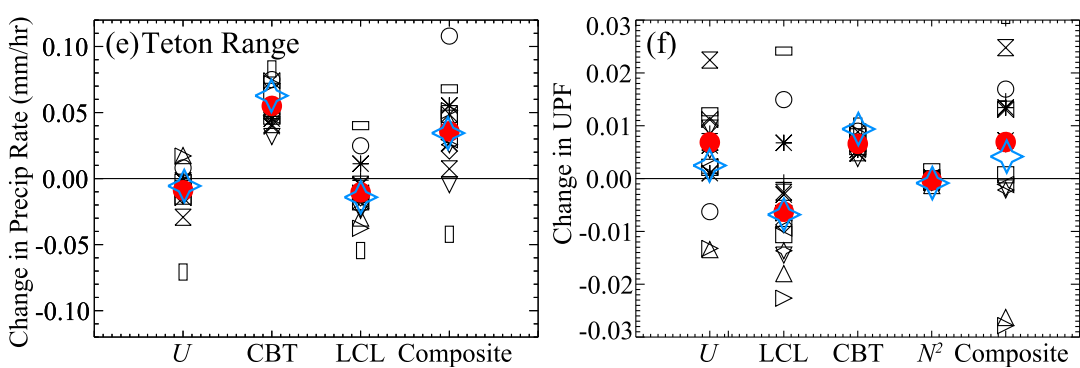

- Ensemble Mean

$\downarrow$ Fitted using RCM output

FIG. 14. Changes in wintertime (left) precipitation rate and (right) UPF predicted by different ambient factor(s). The black symbols indicate the change in precipitation rate and UPF that are estimated from the changes in ambient factors from different CMIP5 GCMs, and the red dots indicate the change in precipitation rate and UPF estimated from the ensemble-mean changes in ambient factors from the 15 GCMs. The blue stars are the fitted results using RCM hourly output and are the same as the blue stars in Fig. 12.

$\sim 1995$ and $\sim 2050$ are estimated from the CMIP5 GCM ensemble-mean high-end emission scenario, and are applied to the WRF simulation using the PGW technique. This scenario has a winter surface temperature warming of about $2.2 \mathrm{~K}$ in the IWUS. The change in wintertime precipitation rate and distribution and the controlling ambient factors are examined based on the previously developed statistical approach that relates orographic precipitation rate (as well as UPF) to different ambient parameters. We focus on three mountain ranges in the IWUS: the Wind River, Park, and Teton Ranges. The main findings are as follows:

1) The CMIP5 predicted changes result in a $1-2 \mathrm{~K}$ increase in cloud-base and cloud-top temperatures but minimal changes in cloud depth in the IWUS. The low-level wind speed is reduced by less than $1 \mathrm{~m} \mathrm{~s}^{-1}$, and the low-level stability decreases slightly.

2) Wintertime precipitation increases in most areas of the IWUS in a warming climate, mostly over the mountains, although the relative increase is higher over the plains and basins than over the mountains. The precipitation rate during winter storms increases in most regions, but the duration of precipitation events increases only over plains. One region where no increase in wintertime precipitation is predicted is the area in the lee (i.e., the east side) of mountain ranges.

3) The increase in precipitation rate in winter storms is mainly the result of atmospheric moisture increase in a warmer climate. The weakening of crossmountain winds tends to offset the precipitation

TABLE 4. Mean changes and standard deviations in precipitation rate (PR) and UPF over the Wind River, Park, and Teton Ranges calculated from WRF and 15 CMIP5 GCM simulations using Eqs. (2) and (3).

\begin{tabular}{lccc}
\hline \hline & Wind River & Park & Teton \\
\hline PR $\left(\mathrm{mm} \mathrm{h}^{-1}\right)$ & $0.049 \pm 0.041$ & $0.065 \pm 0.059$ & $0.049 \pm 0.038$ \\
UPF & $0.016 \pm 0.023$ & $0.009 \pm 0.023$ & $0.002 \pm 0.017$ \\
\hline
\end{tabular}


increase, but its impact is secondary. The distribution of precipitation on opposite sides of mountain crests changes little.

4) The 15 CMIP5 ensemble members are statistically downscaled using the previously developed empirical relationships between precipitation and ambient parameters. There is a wide range of predictions of changes in orographic precipitation and its distribution across ranges among the individual CMIP5 members, although 13 of the 15 CMIP5 models agree that the wintertime orographic precipitation increases in a warmer climate.

Acknowledgments. This work was funded by the Wyoming Water Development Commission and the U.S. Geological Survey, under the auspices of the University of Wyoming Water Research Program, and by the U.S. National Science Foundation Grant AGS-1547101. The lead author was funded by a Wyoming Engineering Initiative Doctoral Fellowship and by the Startup Foundation for Introducing Talent of NUIST.

\section{REFERENCES}

Bender, F. A.-M., V. Ramanathan, and G. Tselioudis, 2012: Changes in extratropical storm track cloudiness 1983-2008: Observational support for a poleward shift. Climate Dyn., 38, 2037-2053, https://doi.org/10.1007/s00382-011-1065-6.

Colle, B. A., 2004: Sensitivity of orographic precipitation to changing ambient conditions and terrain geometries: An idealized modeling perspective. J. Atmos. Sci., 61, 588-606, https:// doi.org/10.1175/1520-0469(2004)061<0588:SOOPTC $>2.0 . C O ; 2$.

Das, T., D. W. Pierce, D. R. Cayan, J. A. Vano, and D. P. Lettenmaier, 2011: The importance of warm season warming to western US streamflow changes. Geophys. Res. Lett., 38, L23403, https://doi.org/10.1029/2011GL049660.

Deser, C., L. Terray, and A. S. Phillips, 2016: Forced and internal components of winter air temperature trends over North America during the past 50 years: Mechanisms and implications. J. Climate, 29, 2237-2258, https://doi.org/10.1175/ JCLI-D-15-0304.1.

Dettinger, M., 2014: Climate change: Impacts in the third dimension. Nat. Geosci., 7, 166-167, https://doi.org/10.1038/ngeo2096.

Eidhammer, T., V. Grubišić, R. Rasmussen, and K. Ikeda, 2018: Winter precipitation efficiency of mountain ranges in the Colorado Rockies under climate change. J. Geophys. Res. Atmos., 123, 2573-2590, https://doi.org/10.1002/2017JD027995.

Fu, G., M. E. Barber, and S. Chen, 2010: Hydro-climatic variability and trends in Washington State for the last 50 years. Hydrol. Processes, 24, 866-878, https://doi.org/10.1002/hyp.7527.

Garvert, M. F., B. Smull, and C. Mass, 2007: Multiscale mountain waves influencing a major orographic precipitation event. J. Atmos. Sci., 64, 711-737, https://doi.org/10.1175/JAS3876.1.

Geerts, B., Y. Yang, R. Rasmussen, S. Haimov, and B. Pokharel, 2015: Snow growth and transport patterns in orographic storms as estimated from airborne vertical-plane dual-Doppler radar data. Mon. Wea. Rev., 143, 644-665, https://doi.org/10.1175/ MWR-D-14-00199.1.
Gutmann, E. D., J. Hamman, T. Eidhammer, K. Nowak, J. Arnold, and M. P. Clark, 2017: Leveraging past climate variability to inform methodological choices and improve hydrologic projections. 2017 Fall Meeting, New Orleans, LA, Amer. Geophys. Union, Abstract H42C-01, https://agu.confex.com/agu/fm17/ meetingapp.cgi/Paper/209730.

Hong, S. Y., and H. L. Pan, 1996: Nonlocal boundary layer vertical diffusion in a medium-range forecast model. Mon. Wea. Rev., 124, 2322-2339, https://doi.org/10.1175/1520-0493(1996) $124<2322:$ NBLVDI $>2.0$.CO;2.

Houze, R. A., Jr., 2012: Orographic effects on precipitating clouds. Rev. Geophys., 50, RG1001, https://doi.org/10.1029/ 2011RG000365.

Hurrell, J., M. Visbeck, and A. Pirani, 2011: WCRP Coupled Model Intercomparison Project-Phase 5. CLIVAR Exchanges, No. 56, CLIVAR Project Office, Southampton, United Kingdom, 51 pp., https://www.gfdl.noaa.gov/bibliography/related_files/ CLIVAR_Exchange_16_2_2011.pdf.

Iacono, M. J., J. S. Delamere, E. J. Mlawer, M. W. Shephard, S. A. Clough, and W. D. Collins, 2008: Radiative forcing by longlived greenhouse gases: Calculations with the AER radiative transfer models. J. Geophys. Res., 113, D13103, https://doi.org/ 10.1029/2008JD009944.

James, C. N., and R. A. Houze Jr., 2005: Modification of precipitation by coastal orography in storms crossing Northern California. Mon. Wea. Rev., 133, 3110-3131, https://doi.org/ 10.1175/MWR3019.1.

Jimenez, P. A., J. J. Dudhia, F. Gonzalez-Rouco, J. Navarro, J. P. Montavez, and E. Garcia-Bustamante, 2012: A revised scheme for the WRF surface layer formulation. Mon. Wea. Rev., 140, 898-918, https://doi.org/10.1175/MWR-D-11-00056.1.

Jing, X., B. Geerts, Y. Wang, and C. Liu, 2017: Evaluating seasonal orographic precipitation in the interior western United States using gauge data, gridded precipitation estimates, and a regional climate simulation. J. Hydrometeor., 18, 2541-2558, https://doi.org/10.1175/JHM-D-17-0056.1.

_ , Y. Geerts, Y. Wang, and C. Liu, 2018: Ambient factors controlling the wintertime precipitation distribution across mountain ranges in the interior western United States. Part I: Insights from regional climate simulations. J. Appl. Meteor. Climatol., 57, 1931-1954, https://doi.org/10.1175/JAMC-D-17-0291.1.

Kirshbaum, D. J., and R. B. Smith, 2008: Temperature and moist-stability effects on midlatitude orographic precipitation. Quart. J. Roy. Meteor. Soc., 134, 1183-1199, https://doi.org/ 10.1002/qj.274.

Letcher, T. W., and J. R. Minder, 2015: Characterization of the simulated regional snow albedo feedback using a regional climate model over complex terrain. J. Climate, 28, 7576-7595, https://doi.org/10.1175/JCLI-D-15-0166.1.

Liu, C., and Coauthors, 2017: Continental-scale convectionpermitting modeling of the current and future climate of North America. Climate Dyn., 49, 71-95, https://doi.org/ 10.1007/s00382-016-3327-9.

Lorenz, D. J., and E. T. DeWeaver, 2007: Tropopause height and zonal wind response to global warming in the IPCC scenario integrations. J. Geophys. Res., 112, D10119, https://doi.org/ 10.1029/2006JD008087.

Luce, C. H., J. T. Abatzoglou, and Z. A. Holden, 2013: The missing mountain water: Slower westerlies decrease orographic enhancement in the Pacific Northwest USA. Science, 342, 1360-1364, https://doi.org/10.1126/science.1242335.

Milly, P. C. D., J. Betancourt, M. Falkenmark, R. M. Hirsch, Z. W. Kundzewicz, D. P. Lettenmaier, and R. J. Stouffer, 2008: 
Stationarity is dead: Whither water management? Science, 319, 573-574, https://doi.org/10.1126/science.1151915.

Minder, J. R., D. R. Durran, G. H. Roe, and A. M. Anders, 2008: The climatology of small-scale orographic precipitation over the Olympic Mountains: Patterns and processes. Quart. J. Roy. Meteor. Soc., 134, 817-839, https://doi.org/10.1002/qj.258.

Mote, P. W., A. F. Hamlet, M. P. Clark, and D. P. Lettenmaier, 2005: Declining mountain snowpack in western North America. Bull. Amer. Meteor. Soc., 86, 39-49, https://doi.org/ 10.1175/BAMS-86-1-39.

Niu, G.-Y., and Coauthors, 2011: The community Noah land surface model with multiparameterization options (Noah-MP): 1. Model description and evaluation with local-scale measurements. J. Geophys. Res., 116, D12109, https://doi.org/10.1029/ 2010JD015139.

Panziera, L., and U. Germann, 2010: The relationship between airflow and orographic precipitation in the Southern Alps as revealed by weather radar. Quart. J. Roy. Meteor. Soc., 136, 222-238, https://doi.org/10.1002/qj.544.

Rasmussen, R., and Coauthors, 2011: High-resolution coupled climate runoff simulations of seasonal snowfall over Colorado: A process study of current and warmer climate. J. Climate, 24, 3015-3048, https://doi.org/10.1175/2010JCLI3985.1.

— , and Coauthors, 2014: Climate change impacts on the water balance of the Colorado Headwaters: High-resolution regional climate model simulations. J. Hydrometeor., 15, 10911116, https://doi.org/10.1175/JHM-D-13-0118.1.

Riahi, K., and Coauthors, 2011: RCP 8.5-A scenario of comparatively high greenhouse gas emissions. Climatic Change, 109 , 33, https://doi.org/10.1007/s10584-011-0149-y.

Saha, S., and Coauthors, 2010: The NCEP Climate Forecast System Reanalysis. Bull. Amer. Meteor. Soc., 91, 1015-1057, https:// doi.org/10.1175/2010BAMS3001.1.

Schär C., C. Frei, D. Lüthi, and H. C. Davies, 1996: Surrogate climate-change scenarios for regional climate models. Geophys. Res. Lett., 23, 669-672, https://doi.org/10.1029/96GL00265.
Shi, X., and D. R. Durran, 2014: The response of orographic precipitation over idealized midlatitude mountains due to global increases in $\mathrm{CO}_{2}$. J. Climate, 27, 3938-3956, https://doi.org/ 10.1175/JCLI-D-13-00460.1.

Siler, N., and G. Roe, 2014: How will orographic precipitation respond to surface warming? An idealized thermodynamic perspective. Geophys. Res. Lett., 41, 2606-2613, https://doi.org/ 10.1002/2013GL059095.

Thompson, G., P. R. Field, R. M. Rasmussen, and W. D. Hall, 2008: Explicit forecasts of winter precipitation using an improved bulk microphysics scheme. Part II: Implementation of a new snow parameterization. Mon. Wea. Rev., 136, 5095-5115, https://doi.org/10.1175/2008MWR2387.1.

Wang, Y., B. Geerts, and C. Liu, 2018: A 30-year convectionpermitting regional climate simulation over the Interior Western United States. Part I: Validation. Int. J. Climatol., 38, 3684- 3704, https://doi.org/10.1002/joc.5527.

Wu, C., X. Liu, Z. Lin, S. R. Rahimi-Esfarjani, and Z. Lu, 2018: Impacts of absorbing aerosol deposition on snowpack and hydrologic cycle in the Rocky Mountain region based on variable-resolution CESM (VR-CESM) simulations. Atmos. Chem. Phys., 18, 511, https://doi.org/10.5194/ acp-18-511-2018.

Yang, Z.-L., and Coauthors, 2011: The community Noah land surface model with multiparameterization options (Noah-MP): 2. Evaluation over global river basins. J. Geophys. Res., 116, D12110, https://doi.org/10.1029/2010JD015140.

Yuter, S. E., D. A. Stark, J. A. Crouch, M. Jordan Payne, and B. A. Colle, 2011: The impact of varying environmental conditions on the spatial and temporal patterns of orographic precipitation over the Pacific Northwest near Portland, Oregon. J. Hydrometeor., 12, 329-351, https://doi.org/10.1175/ 2010JHM1239.1.

Zängl, G., 2008: The temperature dependence of small-scale orographic precipitation enhancement. Quart. J. Roy. Meteor. Soc., 134, 1167-1181, https://doi.org/10.1002/qj.267. 